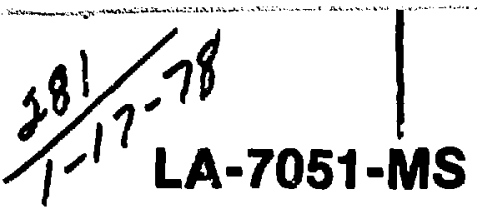

Informal Report

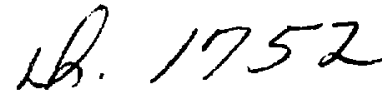

UC-34b and UC.37

Issued: December 1977

\title{
An Instrument for Observing \\ Transient Cosmic Gamma-Ray Sources for the ISEE-C Heliocentric Spacecraft
}

W. D. Evans

W. P. Aiello

R. W. Klebesadel

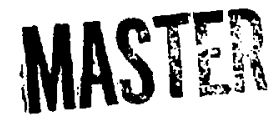

w: $:$

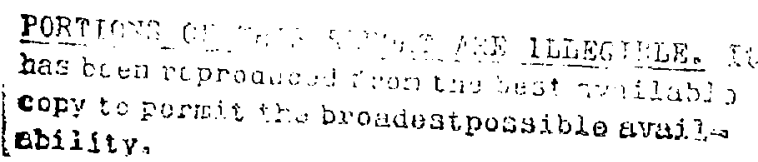




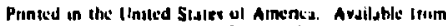
Nutivial Technicul Inturmation Stevice

U.S. Deparimitni in Cummirit

sans Port Ruy dil Roud

Sprnplistd. VA 22161

\begin{tabular}{|c|c|c|c|c|c|c|c|c|c|}
\hline $\begin{array}{l}\text { Mkemitinhs } \\
\text { Im1-1125 } \\
\text { 112-05i1 } \\
1151-1175 \\
1176-103 \\
111-125\end{array}$ & $\begin{array}{r}5.100 \\
400 \\
4.311 \\
5.25 \\
6.00 \\
6.511\end{array}$ & $\begin{array}{l}126.1511 \\
151 \cdot 175 \\
176.21+11 \\
201-225 \\
226-250\end{array}$ & $\begin{array}{l}7.25 \\
8.1911 \\
9.041 \\
9.25 \\
9.911\end{array}$ & $\begin{array}{l}251-275 \\
276-300 \\
301-315 \\
326-350 \\
351-375\end{array}$ & $\begin{array}{l}10.75 \\
11.01 \\
11.75 \\
12 .(6) \\
12.50\end{array}$ & $\begin{array}{r}376-4011 \\
401+25 \\
436-4511 \\
451 \cdot 475 \\
476-5011\end{array}$ & $\begin{array}{l}13.611 \\
13.25 \\
14.01 \\
14.50 \\
15.1111\end{array}$ & $\begin{array}{l}501-525 \\
526-5511 \\
551-575 \\
576-6011 \\
6111-u p\end{array}$ & $\begin{array}{l}15.25 \\
15.5 n \\
16.25 \\
16.5 n \\
-.1\end{array}$ \\
\hline
\end{tabular}

1. Add $\$ 2,50$ for each aditional 100-pere increment from 601 pages up.

This report was prepored as an acesust of work spunmired by the United Stukes Gnvernment. Neithre the Uniced Stutes nup the Uniced Slates Deportment of linerav, nor anv of thesr emplosere, nur any of throt cuntractire, subcontracturs, or

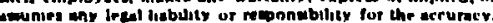
rompletenese, or usefulmess of any infurmallen, apporatus.

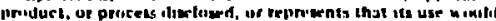
not infrinate pnvelely ow ned nthus. 


\section{AN INSTRUMENT FOR OBSERVING TRANSIENT COSMIC GAMMA-RAY SOURCES FOR THE ISEE-C HELIOCENTRIC SPACECRAFT}

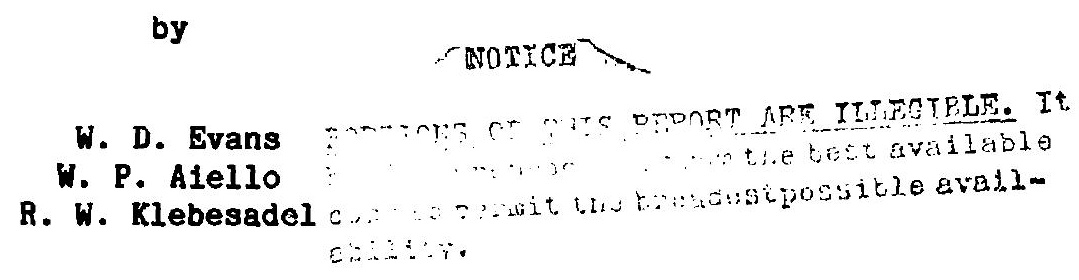

\section{ABSTRACT}

This report describes satellite instrumentation that would serve as one element of a three-satellite network to provide precise directional information for the recently discovered cosmic gamma-ray bursts. The proposed network would be capable of determining source locations with uncertainties of less than one arc minute, sufficient for a meaningful optical and radio search. The association of the gamma bursts with a known type of astrophysical object provides the most direct method for establishing source distances and thus defining the overall energetics of the emission process.

I. INTRODUCTION

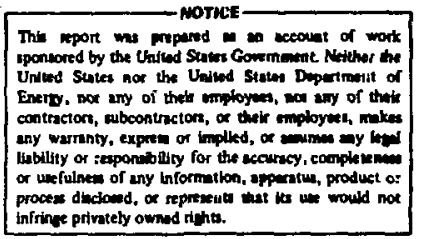

In 1973 Klebesadel et al. ${ }^{1}$ announced the discovery of intense, short-duration bursts of gamma-ray phstons, apparently of cosmic origin. This discovery was based on several years of data from the gamma-ray monitoring detectors on the network of Yela satellites and consisted of the detection of nearly simultaneous increases in the $>0.1-\mathrm{MeV}$ photon flux by several satellites at locations up to $240000 \mathrm{~km}$ apart. This discovery ultimately might have been made by the extensive conparison of data from a variety of detectors on other satellites, but no single counting-rate increase observed with one instrument alone, and occurring only several times per year, would have been sufficies to establish the effect as genuine. In addition, the intersatellite timing provided by 
the Vela system gave a means of determining the direction of propagation of the photon wavefront through space. It is this result that guaranteed that the bursts originated well sutside the Earth's environment. The puclication of this discovery was followed by a number of confirmatory observations and by measurements of some of the spectral, temporal, and directional characteristics of a number of burst events. Cline et al. ${ }^{2}$ showed that the incident flux was unambiguously composed of hard photons, mostly in the 100 to several hundred-keV energy range, and Wheaton et al. ${ }^{3}$ independently found the direction of one event to agree with the source direction determined by the timing measurements from the Vela network. The examination of data from existing experiments during the following year and a half yielded additional time histories, spectral measurements, and directional locations, all of which generally agreed in scope with these initial observations. At the present time a total of 34 events have been identified, the initial detection of 27 having been made by the Vela satellites.

The striking nature of the cosmic gamma bursts resulted in immediate attention from the astrophysical community. The fluxes are extrewely high, completely dominating all celestial and local background. The directionally 1sotropic distribution of the sources indicates either a stellar origin in the galactic neighborhood of the sun or an extragalactic origin. Even at stellar distances, the source luminosities exceed that of solar flares in the same energy range by about 12 orders of magnitude. Rapid fluctuations in intensity with time scales of tens of milliseconds are characteristic of the sources, indlcating a maximum source size of about $5000 \mathrm{~km}$. If the source area is compared with that of a Class $?$ solar flare, the hard photon density in the source volume is at least a factor of $10^{15}$ greater.

The stimulation to theorists from this unexpected phenomenon -here the parameters are so extrame - intense flux, brief duration, fine time structure, and hard spectra - has led to the publication of a large number of hypothetical source models. More than a year after these publications first began to appear, there is still no consensus as to the correct model. The reason is very simple; the existing data, although good enough to be exciting and stimulating for the production of models, are insufficient to provide any critical tests. 
Suggested sources of gamma-ray bursts included supernovae, stellar superflares on magnetic wite dwarf stars, "directed" flares on dwarf stars, nuclear flashes on novae, impacting comets on neutron stars, the accretion of material onto a neutron star from a giant binary companion, radiation from relativistic grains of matter entering the radiation field of the sun, decay of nuclear "goklins" (a kind of super-massive nucleus), the collapse of a dwarf star to a neutron star or black hole due to the accimulation of material from a binary companion or from interstellar waterial, matter-antimatter collisions, enhanced radiations from accretion disks due to supercritical mass flow, radiation accompanying "glitches" on old neutron stars, and several others. It is an imaginative list but, as stated above, the current observational data are inadequate to distinguish between competing theories.

While the instruments on existing satellites will undoubtedly continue to provide the identification of additional gamma bursts, such additional inforiation is unlikely to produce significant observational evidence to further our understanding of the nature of the sourses. New and more sophisticated expsriments are needed to provide detailed spectral and temporal measurements and more precise directional information.

\section{RESEARCH ÄPFROACŸ}

A primary objective of future observations of the transient gama sources is the very precise determination of source directions. The required accuracies of minutes-of-arc cannot be achieved with any presently developed techniques of gawma-ray "telescopes." However, precise intersatellite timing from a network of widely separated detectors can provide the necessary results in a straightforward way. For any two satellites $A$ and $B$ separated by a distance $d$, the angle $\alpha$ between the direction to a distant source and the line joining $A$ and $B$ is:

$$
\cos \alpha=\frac{c \tau}{d}
$$


where: $c=$ velocity of light

$\tau$. = difference in the time of arriyal of whe signal at $A$ and $B$.

The angle $\alpha$ defines a cone which projected onto the celestial spliere gives a circle of possible source locations. Observation from a third satellite provides an independent oircle of possible source locations, and the intersections of the two circles define two possible source locations. The uncertainty in $\alpha$ Ls:

$$
\Delta \alpha=\frac{c \Delta \tau}{d \sin \alpha}=\frac{1}{\sin \alpha}\left(\frac{c \Delta \tau}{d}\right) \text {, and let } T=\frac{d}{c} \text {. }
$$

Thus, the greater the baseline separation between satellites, the wore accurately can the source positions be determined.

This is the same method used with the Vela satellite data to make the origInal determinations of source directions with accuracies of a fow legrees. ( $T *$ 0.8 for the Vela satellites.) W1th the proper implementation of planned NASA satellites it will be possible in the time period 1978-1979 to apply this technique with accuracies improved by almost three orders of magnitude. The three satellites that are most desirable as observing platforms are:

(1) ISEE-A (Mother) - Scheduled for launch in 1977 this satellice will be placed in a highly elliptical earth orbit.

(2) Ploneer Venus Orbiter - To be launched in 1978 this satellite will be placed in an orbit about Venus and will provide an intersatellite baseline of 1 A.U. $(T=500)$.

(3) ISEE-C (Hellocentric) - Also scheduled for a 1978 launch, the Heliocentric is to be placed on the sun-earth line, 0.01 A.U. From the earth. $(T=5)$

Work is currently in progress at the Max Planck Institute for Extraterrestrial Physics to nodify an instrument for the ISEE-A satellite to provide the capability for observing the gamma bursts. A LASL proposal for a ganma burst detector for the Venus Orbiter has been accepted by IASA and Is currently being Inplemented. 
Since the planning for the Heliosentric Mission (ISEE-C) had progressed beyond the initial payload selection, the possibility of modifying an already planned experjment to provide the capability for gamma-ray observations was an attractive alternative to Including a new experiment. The Solar X-Ray Spectrometer Experiment, proposed by the University of California, Berkeley Space Sciences Laboratory (UCBSSL) and Included as a part of the Heliocentric payload, was ideally suited for such a modification. The scintillation detector portion of the spectrometer provides the basic detector for the gama-ray observations. The nounting position above the satellite body yields a field of view of approxImately $2 \pi$ steradians without serious absorption effects in the gamma-ray energy range. The orientation o: the scintillation detector (symmetry axis parallel to the spacecraft spin axis) also uinimizes the problem of varying sensitivity produced by spacecraft rotation.

There were, however, three areas of the Solar X-Ray Spectrometer sensor that required some changes: the scintillator crystal geometry, the collimator system, and the photon energy range covered by the experiment. The original configuration of the NaI scintillation crystal (a cylindrical section 7.6-cm 0.d., $6.6-\mathrm{cm} 1.0 ., 2.5 \mathrm{~cm}$ long and mounted with the cylindrical axis parallel to the photomultiplier tube axis) was chosen to provide azimuthal symmetry with maximum area when viewed perpendicular to the symmetry axis, while minimizing the effective volume for charged particle interactions. This configuration provided an unacceptabiy small effective area for energetic photons and an undesirable var1ation in effective area with polar angle. Both difficulties were removed to a large extent by simply decreasing the inside diameter of the cylindrical section. However, unless other changes were made, the increased mass of the scintillation crystal would result in an increase in the background count rate from charged particle interactions. Tc counteract this, in large part, the entire crystal was surrounded by a thin plastic scintillator in a phoswich geometry to reject charged particle counts.

Collimatcr plates are used to restrint the field of view of the $x$-ray spectrometer to $\pm 5^{\circ}$ polar angle about the plane perpendicular to the detector symmetry axis. Since a full $4 \pi$ field of view is desirable for gamma-ray observations, it is necessary that the collimator plates be transparent to photons of energy greater than $150 \mathrm{keV}$. 
The original experiment covered (with the sointillation detector) the energy range 12-228 keV with eight differential energy channels and also provided two Integral energy channels for photon eneagles > $228 \mathrm{keV}$ and > $500 \mathrm{keV}$. To provide improved energy spectra at higher photon energies, three additional level discriminators were included at energies of 356, 740, and $1250 \mathrm{keV}$. The modifled systen provides twelve differential energy channels (SC-1 through SC-12) over the range 12-1250 keV, with the six highest energy chennels (132-1250 keV) of prinary interest for the gama-ray observations. One channel (PG) containing the count rate in the plastic guard scintillator is also provided. Three additional wide channels SC-13, SC-14, and SC-15 have been formed curresponding to the energy intervals 12-36, 36-68, and 68-132 keV. In case of a large solar $x$-ray burst, high time resolution data from these three channels is autonatically stored in the memory residing in the LASL cosmic $\gamma$-ray package and is read out in the telemetry after the $x$-ray burst is over. The resulting energy channels and their corresponding time resolution for the $x$-ray data are listed in Table I.

It should be emphasized that the basic solar x-ray data will be avallable in real time even when the memory is being read out. Thus, the experiment will monitor continuously the solar $x$-ray emission over the entire spectral range of 6-1250 keV.

\section{LASL COSHIC GAMMA-RAY EXPERIMENT}

The required additions to the Solar X-Ray Experiment consist entirely of electronios and include the woessary loglcs and solid state memory for controlling and storinf; the large amounis of data accumulated during the observation of a translent garma-ray source. The several functions of the LASL memory package can be defined as follows: (1) to provide a semiconductor memory with a capacity of 3276,8 bits configured as $2048 \times 16$ bic words, sufficient to store the time histor's and pulse helght spectrum for the largest anticipated gamma burst; (2) to detect a rapid increase in gama-ray count rate and to initiate a high data-rate mode during which the data are stored in the menory for subsequent read out via telenetry; (3) to provide \& priority system whici vill automat1cally allocate the memory to solar $x$-ray events or to cosmic $\gamma$-ray events in accordance with a predetermined set of conditions. The memory is, thus, 
TABLE I

ISEE-C (HELIOCENTRIC) SOLAR X-RAY SPECTROMETER

ENERGY CHANNELS AND _. RESOLUTION

\begin{tabular}{|c|c|c|c|c|c|c|c|c|}
\hline \multirow[b]{3}{*}{ Detector } & \multirow{3}{*}{$\begin{array}{l}\text { X-rng } \\
\text { Emerw } \\
\text { Renge } \\
\text { (keV) }\end{array}$} & \multirow[b]{3}{*}{ Symbol } & \multicolumn{6}{|c|}{ Time Resolution (aes) } \\
\hline & & & \multirow{2}{*}{$\begin{array}{l}\text { Normal } \\
\text { Mode } \\
\text { (Penl } \\
\text { Time } \\
\text { Data) }\end{array}$} & \multicolumn{2}{|c|}{ Flare-1 Mode } & \multicolumn{2}{|c|}{ Flare-2 Mode } & \multirow{2}{*}{$\begin{array}{l}\text { Memory } \\
\text { Read Out } \\
\text { Mode } \\
\text { (Real } \\
\text { Tlmo } \\
\text { Deta) }\end{array}$} \\
\hline & & & & $\begin{array}{l}\text { Real } \\
\text { Time } \\
\text { Date }\end{array}$ & $\begin{array}{l}\text { Stored } \\
\text { Date }\end{array}$ & $\begin{array}{l}\text { Real } \\
\text { Time } \\
\text { Data }\end{array}$ & $\begin{array}{l}\text { Stored } \\
\text { Data }\end{array}$ & \\
\hline \multirow{9}{*}{$\begin{array}{l}\text { Proportloral } \\
\text { Counter }\end{array}$} & C.0-7. 5 & PC1 & 0.3 & 0.8 & $\cdots$ & 0.5 & 1.0 & 1.0 \\
\hline & $7.5-8.5$ & PC2 & 0.5 & 0.3 & $\cdots$ & 0.5 & 4.0 & t. 0 \\
\hline & $8.5-10$ & PCS & 0.5 & 0.5 & -- & 0.5 & 4.0 & 4.0 \\
\hline & $10-12$ & PC4 & 0.5 & 0.3 &.-- & 0.5 & 4.0 & 4.0 \\
\hline & $12-16$ & PCS & 4.0 & 4.0 & & 4.0 & & \\
\hline & $18-20$ & PC6 & 4.0 & 4.0 & & 4.0 & & \\
\hline & $0-0.5$ & PC? & $\cdots$ & 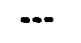 & $0.28 *$ & $\cdots$ & $\cdots$ & $\cdots$ \\
\hline & $0.5-12$ & PC: & $\cdots$ & $\cdots$ & $\cdots$ & +- & 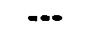 & $\cdots$ \\
\hline & $12-20$ & PCO & $\cdots$ & $\cdots$ & 0.5 & $\cdots$ & 16.0 & 10.0 \\
\hline \multirow{15}{*}{$\begin{array}{c}\text { Nal (TI) } \\
\text { selntiliteres }\end{array}$} & $12-20$ & sci & 0.5 & 0.5 & $\cdots$ & 0.5 & 1.0 & 8.0 \\
\hline & $20-38$ & $\operatorname{sc2}$ & 0.8 & 0.5 & $\cdots$ & 0.8 & 4.0 & 4.0 \\
\hline & $36-52$ & $\operatorname{scs}$ & 0.8 & 0.8 & $\cdots$ & 0.8 & 4.0 & 4.0 \\
\hline & $52-80$ & sct & 0.5 & 0.8 & $\cdots$ & 0.5 & 4.0 & 4.0 \\
\hline & $60-100$ & scs & 0.5 & 0.3 & $\cdots$ & 0.5 & 4.0 & 4.0 \\
\hline & $100-132$ & $\operatorname{sco}$ & 0.8 & 0.5 & $\cdots$ & 0.5 & 4.0 & 1.0 \\
\hline & $132-164$ & $\operatorname{sct}$ & 0.5 & 0.5 & $\cdots$ & 0.5 & 2.0 & 4.0 \\
\hline & $164-228$ & sco & 1.0 & 1.0 & $\cdots$ & 1.0 & 2.0 & 4.0 \\
\hline & $228-556$ & sce & 1.0 & 1.0 & $\cdots$ & 1.0 & 4.0 & 16.0 \\
\hline & $358-484$ & $\operatorname{sc10}$ & 2.0 & 2.0 & $\cdots$ & 2.0 & 16.0 & 18.0 \\
\hline & $444-740$ & scir & 2.0 & 2.0 & $\cdots$ & 2.0 & 160 & $\cdots$ \\
\hline & $740-1250$ & $\operatorname{sc12}$ & 4.0 & 1.0 & $\cdots$ & 4.0 & $\cdots$ & 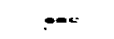 \\
\hline & $12-34$ & $\operatorname{scis}$ & $\cdots$ & $\cdots$ & C. $125 *$ & $\cdots$ & $1.0 *$ & $0.5 *$ \\
\hline & $30-68$ & scta & $\cdots$ & $\cdots$ & 0.128 & $\cdots$ & 1.0 & 0.5 \\
\hline & $6 e-132$ & $\operatorname{sccs}$ & $\ldots$ & $\cdots$ & 0.125 & $\cdots$ & 1.0 & 0.5 \\
\hline Placte Guard & & PG & 4.0 & 4.0 & 1.0 & 4.0 & 18.0 & 18.0 \\
\hline Frame Counter & & $=-$ & $=--$ & $\cdots$ & 3.0 & $\cdots$ & 4.0 & \\
\hline Tolnl Bitelees & & & 204.0 & 208.0 & 258.0 & 201.0 & 08.0 & 10.0 \\
\hline
\end{tabular}

-Could be aevigned to enolher channel to command.

'Telemetry rate $20 t 5$ blel ane. 
avallable to the solar x-ray portion of the experiment for storing strong solar flare data. In fact, since gamma events are expected to occur only a few times a year, the medinry will be available for use by the solar x-ray portion of the experiment most of the time.

Figure 1 shows a simplifled block diagram of the electronics for the LASL coswic y-ray experiment. Data from the six highest differential energy channels of the scintillation detector, SC.7 through SC-12, are furnished, in parallel, to this portion of the memory logics. A seventh channel, called the ST channel, is generated from the sum of the six energy channels. This sum is used to provide the high resolution time-history of the ganma-ray event. Each of the energy channels, SC-7 through SC-12, is also separately accumulated to provide six channels of Pulse Height Analysis (PHA) data. Figure A-1 of Appendix A shows that portion of the logics which accumulates the six scintillation counter energy channels in parallel, and generates the sum or ST channel. Note that Appendix A contains the complete set of sohematic diagrams for the LASL cosmic r-ray experiment.

\section{DATA HANDIING LOGIC}

Table II gives the accumulation times for the various channels for cosmic Banna-ray data. As indlcated in the table, data may be accumulated in two modes, fixed-time and time-to-spill. For the fixed-time mode of operation, twelve successive 11.71875-ms samples of the ST channel counts are accumulated in a 6-bit scalar while, simultaneously, 140.625-ms accumulations of the six pulse height chanriels, SC-7 through SC-12, are recorded. Note that the accumulation time for the pulse height channels is equal to the sum of twelve ST channel accumliations. The tiwe required for one ST channel accumulation in the fixed time mode is equal to the time required to record 48 counts at a $4096-\mathrm{Hz}$ clock rate. The twelve successive 6-bit time history samples (72 bits) are packed electronically into sine 8-bit words so that the data can be organized into blocks conaisting of nine \&-bit (packed) time history words covering 140.625-ms and one 8-bit word for each of the six pulse height channels accumulated over the same 140.625-ms interval as the twelve time histcry samples. The blook of deta generated thus contains a total of 120 bits. Figure 2 11lustrates the contiguration of a typical block of gamma data. 


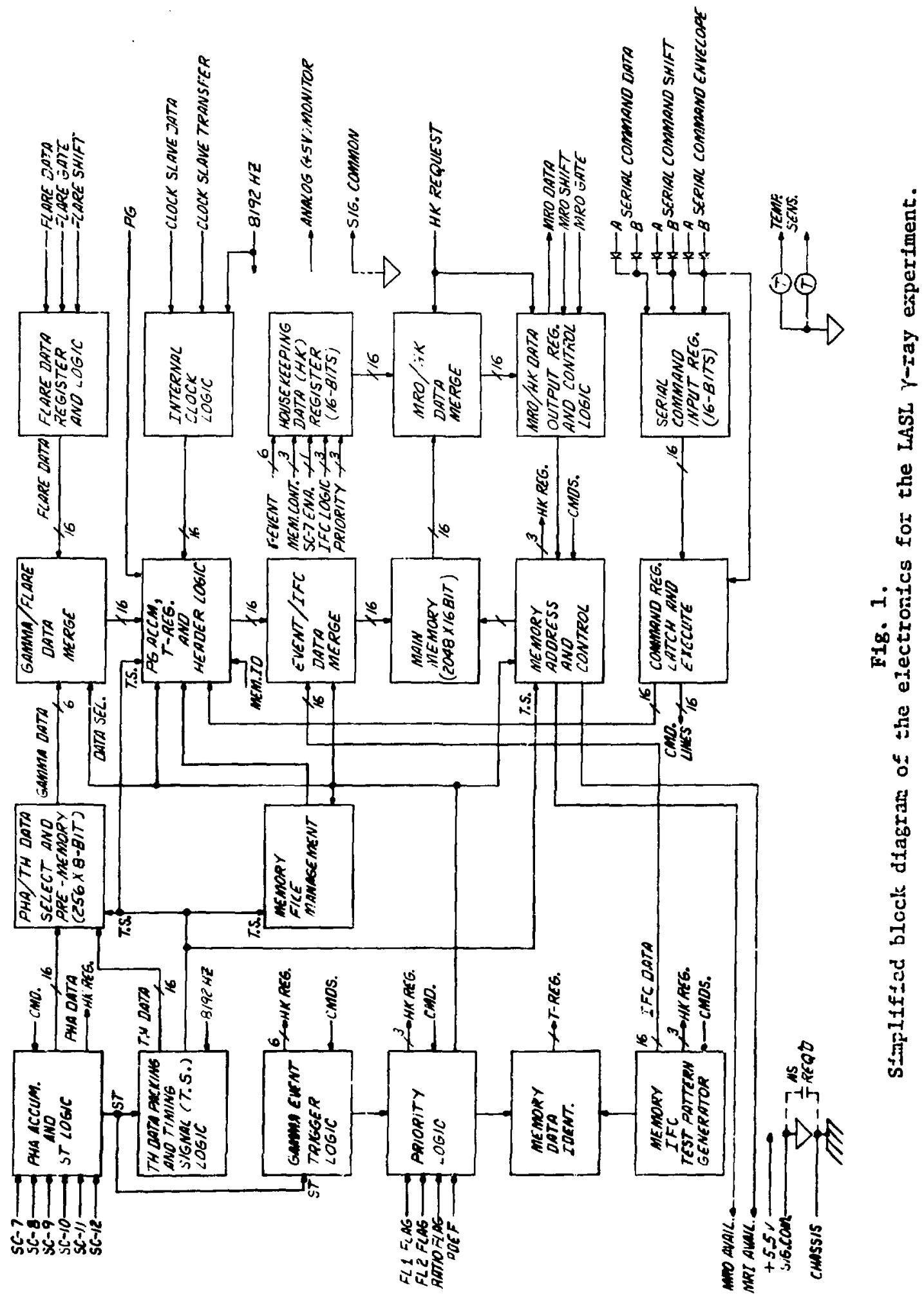


TABLE II

COSYIC GAMA-RAY ENERGY CHANNELS AND TIME RESOLUTIOA

\begin{tabular}{|c|c|c|c|c|}
\hline $\begin{array}{c}\text { Energy } \\
\text { Level (key) }\end{array}$ & Channel & $\begin{array}{c}\text { Bits Per } \\
\text { Accuinulation }\end{array}$ & $\begin{array}{c}\text { Fixed Time Hode } \\
\text { Accum. Time }\end{array}$ & $\begin{array}{c}\text { Time to Spill Hode } \\
\text { Accum. Time }\end{array}$ \\
\hline $\begin{array}{l}132-164 \\
164-228 \\
228-356 \\
356-484 \\
484-740 \\
740-1250 \\
132-1250\end{array}$ & $\begin{array}{l}\text { SC-7 } \\
\text { SC-8 } \\
\text { SC-9 } \\
\text { SC-10 } \\
\text { SC-11 } \\
\text { SC-12 } \\
\text { ST }\end{array}$ & $\begin{array}{l}8 \\
8 \\
8 \\
8 \\
8 \\
8 \\
6\end{array}$ & $\begin{array}{l}140.625 \mathrm{~ms} \\
140.625 \mathrm{~ms} \\
140.625 \mathrm{~ms} \\
140.625 \mathrm{~ms} \\
140.625 \mathrm{~ms} \\
140.625 \mathrm{~ms} \\
11.71875 \mathrm{~ms}\end{array}$ & $\begin{array}{l}>2.928 \mathrm{~ms},<140.625 \mathrm{~ms} \\
>2.928 \mathrm{~ms},<140.625 \mathrm{~ms} \\
>2.928 \mathrm{~ms},<140.625 \mathrm{~ms} \\
>2.928 \mathrm{~ms},<140.625 \mathrm{~ms} \\
>2.928 \mathrm{~ms},<140.625 \mathrm{~ms} \\
>2.928 \mathrm{~ms},<140.625 \mathrm{~ms} \\
>0.244 \mathrm{~ms},<11.71875 \mathrm{~ms}\end{array}$ \\
\hline
\end{tabular}

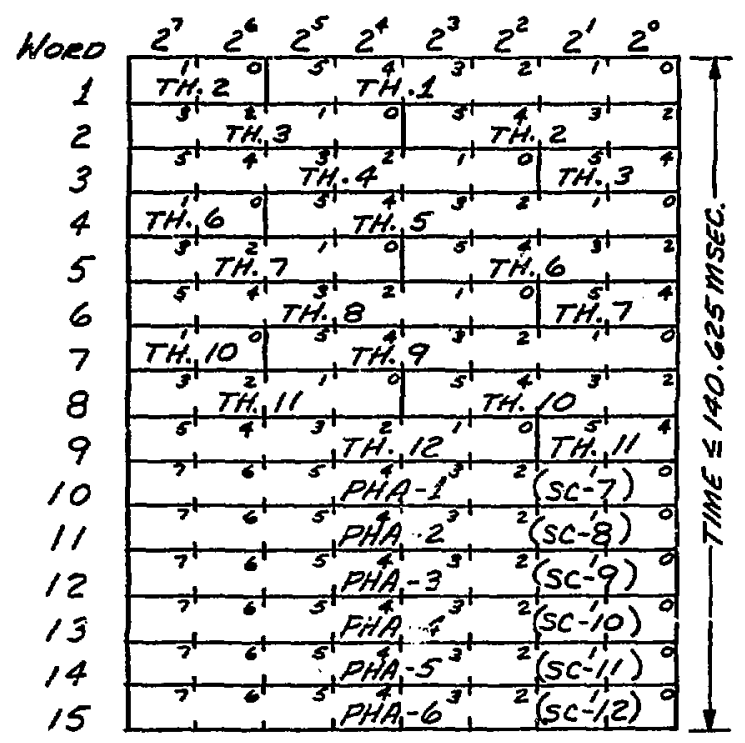

F1g. 2.

GALMA DATA BLOCR

Configuration of a typical gamma data block consisting of 12 6-bit time history words packed into nine 8-bit words plus six 8-bit PHA words for a total of 15 8-bit words (120 btcs).
To allow for the possibility of very high count rates, the gamma loglos are designed to switch automatically to a time-to-spill mode when needed. This is accomplished by roquiring that no ST channel accumulation exceeds 16 counts. If 16 counts are recorded before the end of an 11.71875-ms sample period, that sample period is immediately terminated and the time required to accumulate the 16 counts is recorded in the ST data latch. In this mode of operation, the ST accumulation times will be varlable as indicated in Table II, but the data are organized in the same way as for the fixed time mode, that 1s, twelve successive TH (Time History) samples and one sample each from the six pulse helght channel fors one block of gama data. Figure A-2 in Appendix A is a schematic diagram of the time history and 


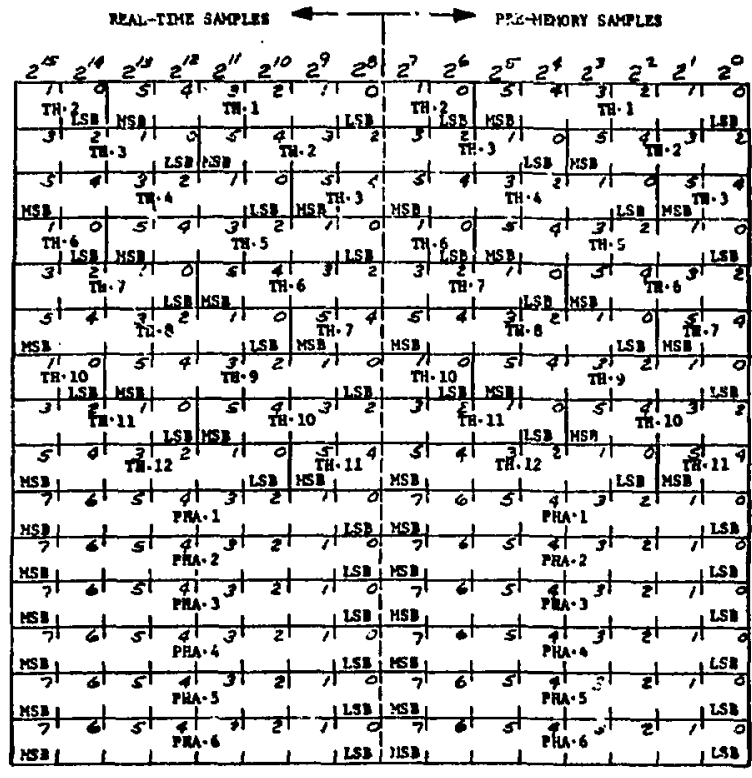

Fig. 3.

Configuration of two gamma data blocks side by side in memory.

TABLE III

T-REGTSTER WORD LIST (GEADER)

\begin{tabular}{|c|c|}
\hline WRDD & DESCRIPTION \\
\hline 1 & Sync. Word 1 \\
\hline 2 & Sjac. Word 2 \\
\hline 3 & Corand Register Status \\
\hline 4 & Mamory Data Ident. \\
\hline 5 & Tios (Btgh Order 16 Bite) \\
\hline 6 & Tine (Low Order 16 Bt(e) \\
\hline 7 & Flage Status \\
\hline 8 & Flage Statue \\
\hline 9 & $\begin{array}{l}\text { Y-Men. File Counter/PG Accu. } \\
\text { (Algh Order } 4 \text { B1ts) }\end{array}$ \\
\hline 10 & PG Accul. (Low Order 16 B1te) \\
\hline 11 & Comand Reglater Status \\
\hline 12 & Manory Data Ident. \\
\hline 13 & Tine (A1ph Order 16 Blte) \\
\hline 14 & TIe (Low Otder $16 \mathrm{stta}$ ) \\
\hline 15 & Sync. Word 2 \\
\hline 16 & Syac. Word 2 \\
\hline
\end{tabular}

MOrL: The word nubers Indicace the order in whtch the correspondias worde appear in the wain wasty header.
PHA data handling and timing logic and Fig. A-3 is a schematio of logic used to temporarily store and pack the twelve 6-bit time history samples into rilne 8-bit words.

\section{ORGANIZATION OF GAMMA DATA IN MEYORY}

The gamma data is further organized into Date Groups consisting of 16 Gamma Data Blooks (240 words $\times 8$ bits). A prememory consisting of $256 \times 8$-bit words is used to store 17 data blooks plus 1 word, of which 16 data blocks or $2.25 \mathrm{~s}$ of data before a gamma event trigger are transferred into the main wewory in parallel with 16 data blooks (2.25 s) of real time data following a gama event trigger. Figure 3 shows the configuration of two gamma data blocks side by side in memory. In addition, thirty-two 8bit words are allotted to sync words, command register status, memory data identification, time, siatus of event flags, and plastic guard (PG) accumulations. The thirty-two 8-bit words are formatted as sixteen 16-bit words held in a "T-Register" for transfer into the main memory at the proper time. The contents of the T-register, defined as a "Beader," are listed in Table III and a description of the bits in each word is contained in Table B-I through Table 


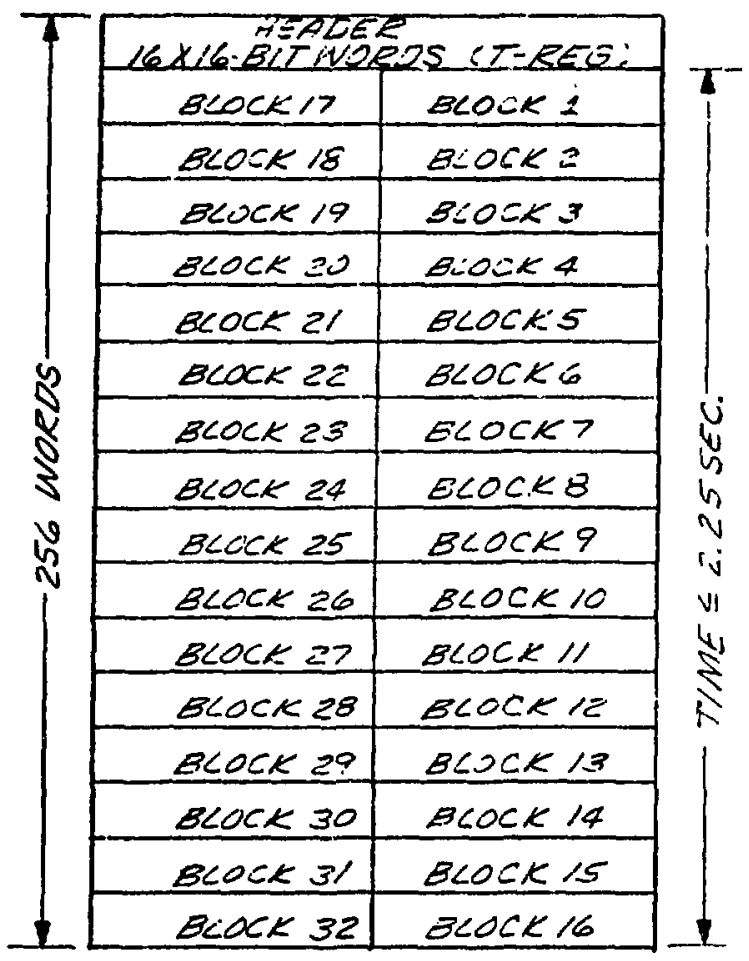

F18. 4.

GAMMA MEMORY FILE

A typical gamma memory file consists of a 16-word header followed by 32 ganma data blocks arranged in patrs as shown. A file is 256 words long by 16 bits wide (4096 b1tg).
B-XI in Appendix B. Figure 4 shows the configuration of a Gamma Mamory File, which consists of the 16-x16-b1t word header followed by 240-x 16-bit words of gamma burgt event data ( 5.50 seconds of data). In Appendix C, Fig. C-1 Indicates the configuration of the pre-memory and main memory after a gamma event trigger and just prior to entering data into the main memory while Fig, $\mathrm{C}-2$ indicates the memory configuration just after the transfer of the first gamma memory file into the main memory. Figures $C-3$ and $C-4$ indicate the memory configuration prior to and after transfer of the 2nd gamma file into the main memory. Shown in Fig. C-5 is the configuration of the main memory when it is full. The total capacity of the memory (2048 $\times 16$ bits) is sufficient to store eight memory files of gamma data. Appendix A contains the detalled schematic diagrams

for the main memory, Fig. A-4, the pre-memory, Fig. A-5, the T-register, Fig. A-6 and the management and control logic for properly entering gamma data into the main memory during an event, Fig. A-7.

\section{vI. GAMM EVENT TRIGGER LOGIC}

Gamma-ray burst events occur infrequently and are of very brief durations, During their brief duration, however, they exhibit complex structure which can be resolved only by sampling at a rapid rate. Telemetry limitations prevent continuous rapid sampling, requiring that a storage capability be employed. The ganma event trigger logics provide a means of sensing statistically significant 
rapid increases in detector event rate in order to automatically initiate a data storage sequence.

The trigger circuit maximizes sensitivity to rapidly rising transients to a degree consistent with immunsty from statistical fluctuations and long-term variations in the natural backgrounds. Figure 5 is a block diagram of the logics required to detect a gamma burst. The circuit incorporates a background accumulator ( $M$ counter) reset on $16-s$ time base, which generates a reference (M count) upon which the trigger levels are based. Three trigger channelo are provided, with periods of $1 / 4,1$, and $2 \mathrm{~s}$, in order to optimize sensitivity over a wider range of signal rise-time.

The anticipated accumulations of background counts in each of the trigger intervals is obtained by appropriately shifting the contents of the nM counter," because the trigger periods are binary submultiples of the 16-s M-counter period. Also, a statistical increment of approximately 5.6 standard deviations is derived fron the $M$ counter. The statistical increment may be, upon comand, multiplied by a factor of 1 or 2 .

The sums of the anticipated accumulations and their respective statistical increments are loaded into comparators. In order to remain within the range of the 8-bit scalers, the numbers loaded into the 1- and 2-s trigger comparators are shifted by 2 and 3 bits respectively, and inputs to those trigger accumulators are prescaled by factors of 4 and 8 . When the level of the trigger accumulator attains that of the comparator, the comparator produces an output that initiates a storage sequence. Trigger accumulators are preset (to -1 ) to accomodate the resolution lost in the references by bit shifting.

The detailed schematic diagrams of the Gamma Event trigger logic are contajned in Appendix A, Figs. A-8 through A-10.

\section{PRIORITIES AND OPTIONS}

Because, under certain conditions, it is possible that confusion or conflicts can occur between "X-events" and "gamma events," it is necessary that priorities be established, and this is done in the automatic priority logic circuitry shown 


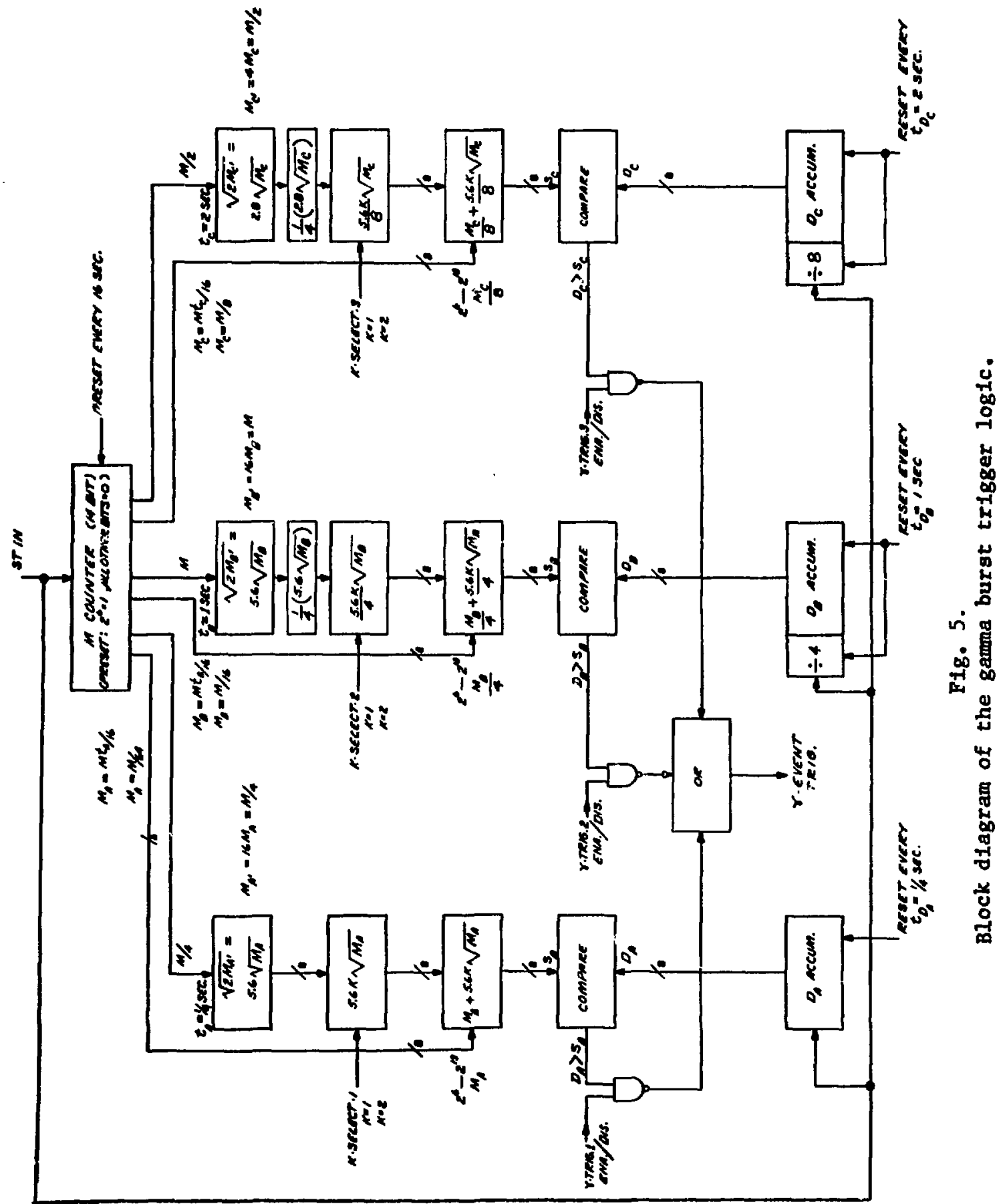


in the detalled schematic diagram of Fig. A-11 in Appendix A. To provide flexibility in the operation of the experiment a preferred or optional scheme can be selected by ground combiand. The various possibilities are lllustrated in Table IV, where the effect of a gamma event and an X-event is shown for each initial state of the system. The preferred final states and the optional final states are listed in the last two columns.

Although it is unlikely, it is possible for either a solar flare or a cosmic gamma burst to cause both the $x$-ray count rate and the gama-ray count rate to exceed the respective "event" thresholds. In this case, the decision between using the memory to store data in the $x$-ray format or the gamma-ray format will be eade on the basis of the spectral distribution of the observed flux. Because solar flare x-ray spectra are usually much "softer" than cosmic gamma burst spectra, the ratio of high-energy photons to low energy photons will be used to determine if simultaneous events should be treated as solar flares or cosmic gamma events. Thus, when the ratio exceeds a preset level, a "Ratio Flag" is sent to the priority logic within the memory system where a decision is made in accordance with the priorities specified in Table IV.

\section{EXPERIMENTAL MODES OF OPERATION}

Depending on the level of the detected $x$-ray emission, the experiment is operated in one of Pive different modes: (1) Normal; (2) Flare I; (3) Flare II; (4) Special Event; (5) Memory Read-Out (MRO). These modes are designed so that optimum time resolution can be obtained for a part of the $x$-ray spectrum during an $x$-ray burst. The time resolution of the data varies with the mode of operation. During the Flare I, Flare II and Special Event modes, the data are stored in the memory and the memory is read out later during the MRO mode.

For most of the time, the experiment will be operating in the Normal Mode where solar $x$-ray data are accumulated and transmitted in real time. At the onset of a solar flare, as detected by a rise in count rate above a selected level of certain PHA channels in the solar $x$-ray portion of the experiment, Flare Mode logic is activated. The Flare $I$ mode is intended to supplement the normal telemetry data with a high time resolution (0.125-s) history of a 
PRIORITIES AND OPTIONS FOR DATA STORAGE AND TELEMETRY FORMATS

\begin{tabular}{|c|c|c|c|c|c|c|}
\hline \multicolumn{2}{|c|}{ Intesal States } & & \multicolumn{4}{|c|}{ F1nel Stulee } \\
\hline \multirow{3}{*}{$\begin{array}{c}\begin{array}{c}\text { Telenecry } \\
\text { Formet }\end{array} \\
\text { Noxal }\end{array}$} & \multirow[b]{2}{*}{$\begin{array}{l}\text { Menory } \\
\text { Status }\end{array}$} & & \multicolumn{2}{|c|}{ Preferred } & \multicolumn{2}{|c|}{ Optlonel } \\
\hline & & & $\begin{array}{c}\text { Telemetry } \\
\text { Format }\end{array}$ & $\begin{array}{l}\text { Memory } \\
\text { Status }\end{array}$ & $\begin{array}{c}\text { Telemetry } \\
\text { Format }\end{array}$ & $\begin{array}{l}\text { Metory } \\
\text { Status }\end{array}$ \\
\hline & Expty & $\begin{array}{l}\text { A Cosmic Gaume } \\
\text { Event Produces: }\end{array}$ & Normal & Y Store & - & $-\infty$ \\
\hline Sorazl & $\begin{array}{l}\text { Conteins an } \\
X \text { Event }\end{array}$ & $\begin{array}{l}\text { A Cosinic Camma } \\
\text { Event Produces: }\end{array}$ & Noranel & Y Store & $\begin{array}{l}\text { No Chang } \\
\text { Intelel }\end{array}$ & $\begin{array}{l}\text { In the } \\
\text { caces }\end{array}$ \\
\hline Noten1. & $\begin{array}{l}\text { Contalns } \\
\text { Gune Evant }\end{array}$ & $\begin{array}{l}\text { A Cosmic Gamma } \\
\text { Event Produces: }\end{array}$ & $\begin{array}{l}\text { No Chan } \\
\text { Inttis }\end{array}$ & $\begin{array}{l}\text { from the } \\
\text { sates }\end{array}$ & $-\infty$ & $-\infty$ \\
\hline xormel & $\begin{array}{l}\text { Ganone Store } \\
\text { in Progrede }\end{array}$ & $\begin{array}{l}\text { An } x \text { Event with "Ratio } \\
\text { Flag" Occurring E1thin } \\
2 \text { Sec } 0 \leq t \leq 2) \\
\text { Produces: }\end{array}$ & Normal & $\begin{array}{l}\text { X store } \\
\text { (Y over- } \\
\text { written) }\end{array}$ & - & - \\
\hline Normal & $\begin{array}{l}\text { Garma Seore } \\
\text { In Progrese }\end{array}$ & $\begin{array}{l}\text { An X Event with "Rat1o } \\
\text { Flag" Occurring after } \\
2 \text { Sec Produces: }\end{array}$ & Normel & $\begin{array}{l}\text { Y Store } \\
\text { Continues }\end{array}$ & - & - \\
\hline $\begin{array}{l}\text { Gave yno } \\
\text { In Prograne }\end{array}$ & - & $\begin{array}{l}\text { A Coemic Gamma } \\
\text { Event Producas: }\end{array}$ & $\begin{array}{l}\text { No Chang } \\
\text { Inftial }\end{array}$ & $\begin{array}{l}\text { frow the } \\
\text { tetes }\end{array}$ & - & - \\
\hline $\begin{array}{l}X \text { yRO in } \\
\text { Prozreas }\end{array}$ & - & $\begin{array}{l}\text { A Cosmic Gama } \\
\text { Event Producea: }\end{array}$ & Normal & $\begin{array}{l}\text { Y Store } \\
\text { (X Event } \\
\text { overwritcen) }\end{array}$ & $\begin{array}{l}\text { No Chane } \\
\text { Inttial }\end{array}$ & $\begin{array}{l}\text { In the } \\
\text { etece }\end{array}$ \\
\hline Nomal & $\operatorname{Ixp} t y$ & $\begin{array}{l}\text { A Flare } 1 \text { X-Evant } \\
\text { Produces: }\end{array}$ & Normal & $\begin{array}{l}\text { X-store } \\
(\vec{r} 1.1)\end{array}$ & - & - \\
\hline Sornal & Eopty & $\begin{array}{l}\text { A Flare } 2 \text { X-Bvent } \\
\text { Produce: }\end{array}$ & Normal & $\begin{array}{l}x-\text { store } \\
(E 2.2)\end{array}$ & $\rightarrow$ & - \\
\hline Yorald & $\begin{array}{l}\text { Contains } \\
\text { Flare } 1 \\
\text { x-Event }\end{array}$ & $\begin{array}{l}\text { A Flare } 2 \text { X-Event } \\
\text { Producea: }\end{array}$ & Normal & $\begin{array}{l}\text { X-Store } \\
\text { (FI. I over- } \\
\text { written) }\end{array}$ & $-\infty$ & $-\infty$ \\
\hline Normal & $\begin{array}{l}\text { Contalne a } \\
\text { Flaro } 1 \text { Evant }\end{array}$ & $\begin{array}{l}\text { A Flare } 1 \text { svent } \\
\text { Produces: }\end{array}$ & $\begin{array}{l}\text { No Chang } \\
\text { Intelal }\end{array}$ & $\begin{array}{l}\text { In the } \\
\text { intes }\end{array}$ & $-\infty$ & - \\
\hline Nornal & $\begin{array}{l}\text { Containe : } \\
\text { Flare } 2 \text { svent }\end{array}$ & $\begin{array}{l}\text { A Flare } 2 \text { Event } \\
\text { Produces: }\end{array}$ & $\begin{array}{l}\text { No Chang } \\
\text { Intt1al }\end{array}$ & $\begin{array}{l}\text { In the } \\
\text { ates }\end{array}$ & - & $-\infty$ \\
\hline Hormal & $\begin{array}{l}\text { Contakne a } \\
\text { Gawa Event }\end{array}$ & $\begin{array}{l}\text { Ar } x \text {-Eveñt } \\
\text { Produces: }\end{array}$ & $\begin{array}{l}\text { No Cheng } \\
\text { Inte1al }\end{array}$ & $\begin{array}{l}\text { In the } \\
\text { :stee }\end{array}$ & Xormen & $\begin{array}{l}\text { X-Store } \\
\text { (Y Data } \\
\text { overwrittea) }\end{array}$ \\
\hline $\begin{array}{l}\text { X-XRO } \\
\text { (Flare 2) }\end{array}$ & $-\infty$ & $\begin{array}{l}\text { An X-Evant } \\
\text { Produces: }\end{array}$ & $\begin{array}{l}\text { No Chang } \\
\text { Int tial }\end{array}$ & $\begin{array}{l}\text { In the } \\
\text { :eted }\end{array}$ & $-\infty$ & - \\
\hline $\begin{array}{l}X-N R O \\
\text { (Elare } 1)\end{array}$ & $-\infty$ & $\begin{array}{l}\text { A Flare } 1 \text { Evant } \\
\text { Produces: }\end{array}$ & $\begin{array}{l}\text { No Chang } \\
\text { Intelal }\end{array}$ & $\begin{array}{l}\text { In the } \\
\text { inter }\end{array}$ & $-\infty$ & $-\infty$ \\
\hline $\begin{array}{l}x-y R 0 \\
\text { (Flare } 1)\end{array}$ & - & $\begin{array}{l}\text { A Flare } 2 \text { Event } \\
\text { Produces: }\end{array}$ & Normel & $\begin{array}{l}\text { X-store } \\
\text { (E1. } 1 \text { over- } \\
\text { vetten) }\end{array}$ & - & - \\
\hline$y+200$ & - & $\begin{array}{l}\text { An X-Event } \\
\text { Producee! }\end{array}$ & $\begin{array}{l}\text { No Chang } \\
\text { Initial }\end{array}$ & In the & - & - \\
\hline
\end{tabular}




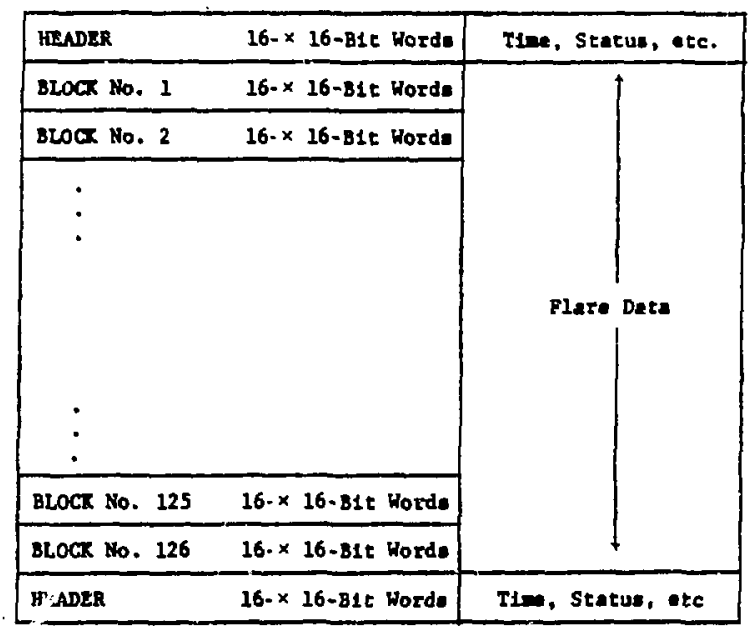

Fig. 6.

Organization of the memory for flare data. portion of the $x$-ray spectrum. These time history data are stored in the semiconductor memory via an $x-r a y$ serial data-input interface between the SSL solar $x$-ray experiment and the LASL Memory Box. The data are read out into telemetry after the cessation of solar flare activity. The Flare II mode is intended to save solar flare spectral information for those solar flares intense enough to interfere with telenetry reception by storing in the memory most of the $x$-ray spectral information at a reduced time resolution. These data are also read out via telemetry at the end of the flare. The organization of the memory for Flare I and Flare II data are shown in Fig. 6 and the header contents are shown in Tabies III and B-I. Notice that Word 4 of the header record contains the information about the type of data being read out. Thus the fourth 16-bit word identifies the data as either Flare I (F1), Flare II (F2), Garma Data (GA), or calibration data.

As previously indicated, the PHA pulse outputs from the scintillation detector channels SC-7 through SC-12 are routed to the memory for processing of "Special Events" having a "hard" or flat $x$-ray spectrum in contrast to the "soft" or steep spectra of normal solar flares. The "Special Events" are rare and take priority over Flare I and Flare II data. The priority logic in the aseary box determines when a transfer to the "Special Event" mode is to be made.

During the memory read-out mode (MRO), real time spectral information is transmitted at a reduced rate to allow telemetry space for the ifho data. The memory contents are read out as 16-bit bytes under the direction of the MRO control logic. The data are shifted into a 16-bit register from which the real time multiplexer shifts 8 bits at a time into the telemetry bit stream in accordance with a predetermined format until the memory is empty. 


\section{TABLE $V$}

LASL/SSL INTERFACE

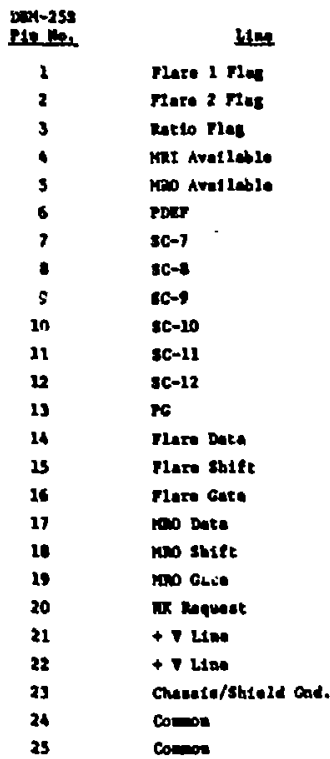

IX. SSL/LASL INTERFACE

The Interface between the SSL Solar X-Ray Experiment and the LASL Memory Unit consists primarily of the Flare serial data-input interface lines, the memory serial data-output interface lines, the SC-7 through SC-12 data input Iines to the memory, and the various flag lines and power lines between the two units. Table $V$ lists these interface lines. Figure A-12 in Appendix $A$ is a schematic diagram that contains the Flare serial interface and data merge logic while Fig. A-13 contains the MRO serlal interface logic.

\section{$X$. THE SPACECRAFT/LASL INTERFACE}

Table VI lists the interface lines between the spacecraft and the LASL Memory Unit. These consist primarily of the serial command interface lines, the slave clock interface lines, the 8192-Hz timing pulse line and two thermistor monitor lines. Upon experiment power turn-on, the x-ray experiment is internally ini-

Aneloz Power Supply Koa. Serial comend zacertace bete sar. Con. Iocer. Data (Redundent)

Serial comend Interface shift Sar. Con. Inter. Shift (kadundent) Ser1el comand laterface Envelope Ser. Cou. Inter. Env. (Reduadent) Marnese shreld t cese fround s18. cou. (Hot conacted is lox) Harnese shleld i cant Grownd

\section{tialized to a quiescent wode of oper-} ation. Before configuring the nxperiment to a more active mode, the nemory must be initialized. This is done by way of the 37-bit serial command to the memory portion of the experiment. The memory utilizes the 
TABLE VII

HOUSEKEEPING DA'TA WORD

\begin{tabular}{|c|c|c|c|c|c|}
\hline $\begin{array}{l}2^{0} \\
2^{1} \\
2\end{array}$ & $\begin{array}{l}\text { ITK } 00 \\
x=01 \\
m x=02\end{array}$ & $\begin{array}{l}x \cdot \text { seLRCT: } 1 \\
X \cdot \operatorname{seLFCT} \cdot 2 \\
X \cdot \operatorname{seLECT} 3\end{array}$ & \multicolumn{3}{|c|}{$\begin{array}{l}0, K=1 ; 1, K=2 \\
0, K=1 ; 1, K=2 \\
0, K-1 ; 1, K=2\end{array}$} \\
\hline $2_{2}^{3}$ & $\begin{array}{l}\text { E*03 } \\
E \cdot 04 \\
\text { ax*05 }\end{array}$ & \multicolumn{4}{|c|}{$\begin{array}{l}\text { Y०TRIG. } 1 \text { ENA./DIS., ENA.-1 } \\
\text { Y०TRIG. } 2 \text { ENA./DIS., ENA.-1 } \\
\text { Y०TRIG. } 3 \text { ENA./DIS., ENA.-1 }\end{array}$} \\
\hline & & & $2^{7}$ & $2^{6}$ & \\
\hline \multirow{2}{*}{$2^{6}$} & \multirow[t]{2}{*}{ Ex-06 } & \multirow{2}{*}{ CAL. SEIECT } & 0 & 0 & ans. \\
\hline & & & $\overline{0}$ & I & CAL. 1 \\
\hline \multirow[t]{2}{*}{$2^{7}$} & \multirow[t]{2}{*}{ : $: 07$} & \multirow[t]{2}{*}{ CAL. SELECT } & $\mathbf{I}$ & 0 & CAl. 3 \\
\hline & & & I & 1 & CAL. 4 \\
\hline
\end{tabular}

$2^{\circ}$ घE08 PRIOKIT HODE SELECT

2 HX.09 MNO SELECT

$2^{10} \quad \mathrm{BR} \cdot 10$ HTS SELECT

\begin{tabular}{|l|l||l|l|}
\hline $2^{10}$ & $2^{9}$ & & HODE \\
\hline 0 & 0 & MRO-1 & AUTO \\
\hline 0 & 1 & KRO-2 & AUTO \\
\hline 1 & 0 & MRO-3 & AUTO \\
\hline 1 & 1 & MRO-1 & ENGUAL \\
\hline
\end{tabular}

$2^{11}$ HX.11 TLNE EVRT TLAO

$2^{12}$ RX' 12 IFC ENA./DIS., ENA.-2

${ }_{2}^{13}$ HX-13 SC-7 ENA./DIS., ENA.-1

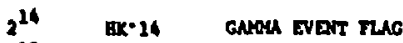

$2^{15}$ ER'15 MEIOAY FULL MAG last 16 bits of the serial command, and these bits are loaded into a holding register at the trailing edge of the command envelope pulse. The command bits are then executed and distributed to the various parts of the experiment. The schematic diagram of the serial command interface logic is shown in Fig. A-14 of Appendix A.

The command status of the memory is read out by way of the 16-bit memory housekeeping (HK) data word. Tables VII and VIII describe each bit In the housekeeping data word and Fig. 7 shows the proper bit pattern for normal memory operation. Figure 8 lists the 16 bits of the serial command. Except for bits 11, 14, and

15. there is correspondence between the housekeeping bits and the command bits. The corresponding command bits are "toggle command," that is, a "1" command bit causes the corresponding configuration control bit to toggle to its complement state.

To initialize the memory, it is necessary to compare the housekeeping bit pattern with the pattern in FIg. 7 to determine which command bits are to be sent.

The serial-slaye clock interface between the spacecraft and the memory is used to synchronize the spacecraft clock with the internal clock in the memory. The conplete spacecraft clock data are transferred at 0.5-s intervals. Consequently, synchronization can be accomplished within $0.5 \mathrm{~s}$ at any bit rate. As indicated in Table III, data from the internal clock in the memory appears on words 5 and 6 in the header record and is repeated in words 13 and 14. 
TABLE VIII

HOUSEKEEPING DATA WORD

Dit Dascription

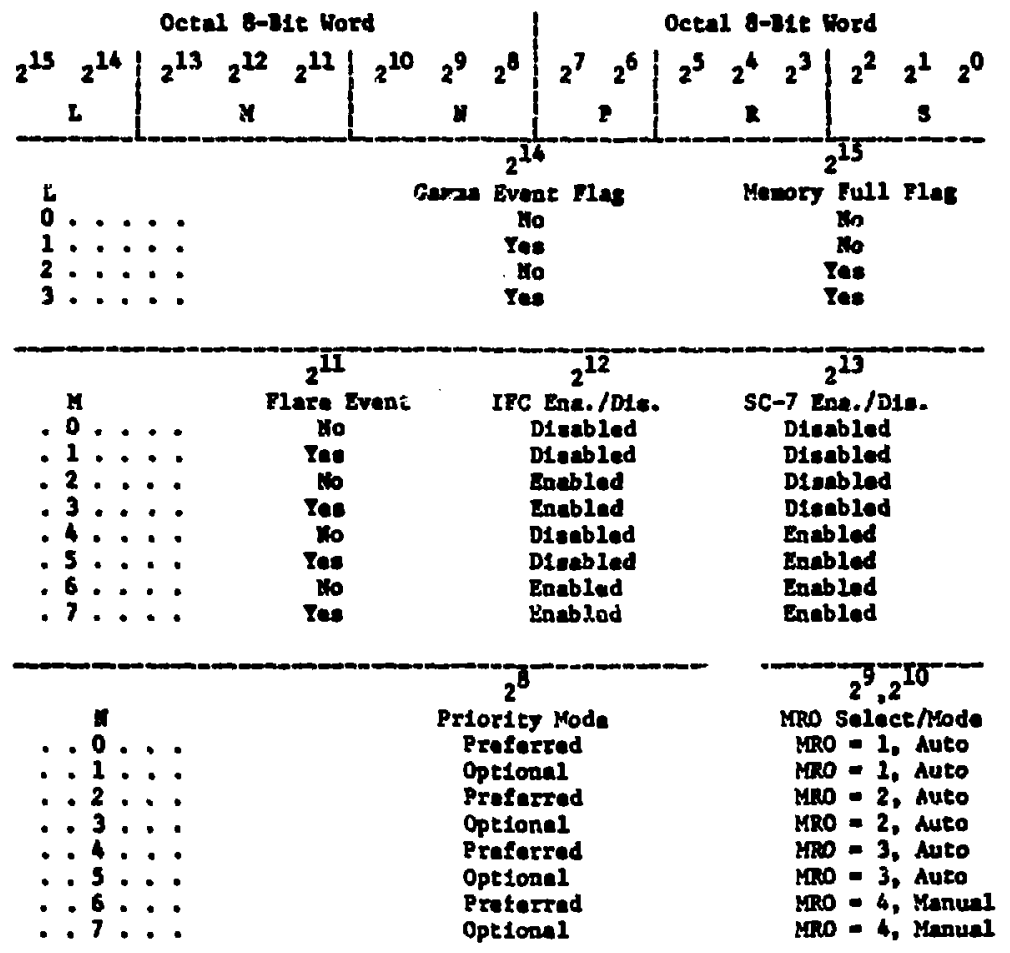

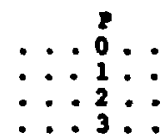

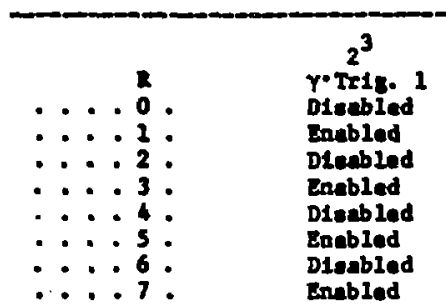

$2^{6} \cdot 2^{7}$

c.1. Seleet

Ca1. 1

cal. 2

cal. 3

Cal.

$2^{4}$
YoTris. 2
Disabled
Dieabled
Enabled
Enabled
Dieabled
Disebled
Enobled
Enabled

$2^{5}$

$Y \cdot T r 1$ - 3

Disabled

Diesbled

Dianbled

Diesbled

Enobled

Enubled

Enublad

Fnubled

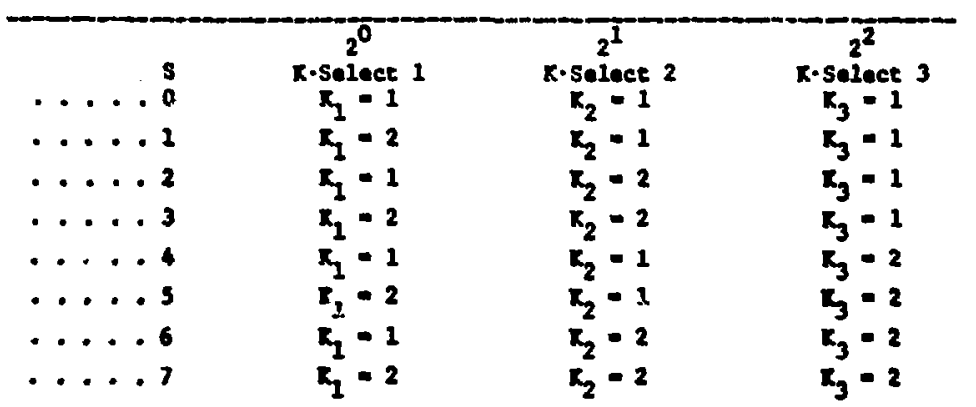




$\begin{array}{cc}\text { IIT } & \text { SHOULD BE } \\ 2^{4} & 0 \\ 2^{1} & 0 \\ 2^{2} & 0 \\ 2^{3} & 2 \\ 2^{4} & 1 \\ 2^{5} & 1 \\ 2^{6} & 0 \\ 2^{2} & 0 \\ 2^{1} & 0 \\ 2^{5} & 0 \\ 2^{20} & 0 \\ 2^{11} & 0 \\ 2^{12} & 0 \\ 2^{13} & 1 \\ 2^{24} & 0 \\ 2^{13} & 0\end{array}$

Fig. 7.

HOUSEKEEPING (HK) DATA WORD

Bit pattern for inftial configuration.

\begin{tabular}{|c|c|c|}
\hline DIt & Mate & \\
\hline $2^{0}$ & x-senzet 1 & TOCGLE Cotentrd \\
\hline 21 & X.3ELCG 2 & TOCGLE COKHASD \\
\hline $2^{2}$ & X'seLCT 3 & TOCGLE COAMND \\
\hline $2^{3}$ & Y'xus. 1 & TOECLE CONHA \\
\hline 24 & r.tuxc. 2 & TOCGLE COASWN \\
\hline $2^{5}$ & r.mIC. 3 & TOCGLE CORUSD \\
\hline $2^{6}$ & CAL. MODE SEL. & TOCGLE CONOHND \\
\hline $2^{7}$ & CAL. MODE SEL. & TOCGLE CONOMND \\
\hline 20 & Prronits yode sel. & TOCGLE COFDUND \\
\hline $2^{3}$ & mo sarer & TOGGLS COHEND \\
\hline $2^{10}$ & Feo setset & ToGoue coneund \\
\hline $2^{31}$ & NSET ILACS & \\
\hline $2^{12}$ & IFC EA./DIs. & TOCGLE Carind \\
\hline $2^{13}$ & SC-7 Euk./DIs. & TOCGLE CONAND \\
\hline $2^{14}$ & conewid Ife & \\
\hline $2^{15}$ & Coneutd yos & \\
\hline
\end{tabular}

$$
\text { Fig. } 8 .
$$

COMMAND DATA WORD.

elect $1=1$

x-select $2=1$

c. SELECT 3 - 1

r.ruc. 1 manco

r.Jug, 2 ENhtLD

$r$ Tug. 3 andero

CAL. 1 MODE SELECES

PREFERED BRIORITY MODE

f.o - 1 SELECTED

mo thare evers thas

rotox IEC disabed

86-7 DWLLd

no GNen EVEST FuA

Moronx IS EPT

\section{LASL INSTRUMENT REQUIREMENTS}

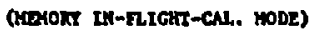

An incremental allocation of $1 \mathrm{~W}$ for power, $1.4 \mathrm{~kg}$ for weight and 1600 $\mathrm{cm}^{3}$ for volume was initially obtained from the Project Cffice to accommodate the LASL memory electronics package. Final figures for the flight unit are $70 \mathrm{~mW}$ for power, $1.271 \mathrm{~kg}$ for weight and $1655 \mathrm{~cm}^{3}$ for volume. The low figure of $70 \mathrm{~mW}$ for power resulted from the lise of Complementary Symmetry Metal Oxide Seniconductor (COSyOS) integrated circuits exclusively throughout the package. A total of 389 integrated circuits were used in the unit. Figure 9 is a photograph of the LASL Instrument package showing the box and three of the ten multilayer electonics boards. A fourth board 18 . shown partially inserted Into the box to 1llustrate the manner in which the boards are inserted and removed.

The SSL solar x-ray experiment, In addition to two other instruments, will be wounted on a tower above the body of the spacecraft. The additional weight of the LASL memory package, if mounted on the tower would have exceeded the maximum allowable tower weight deterwined by the requirement for spin stability. A series of discussions and meetings with SSL, Project office designers 


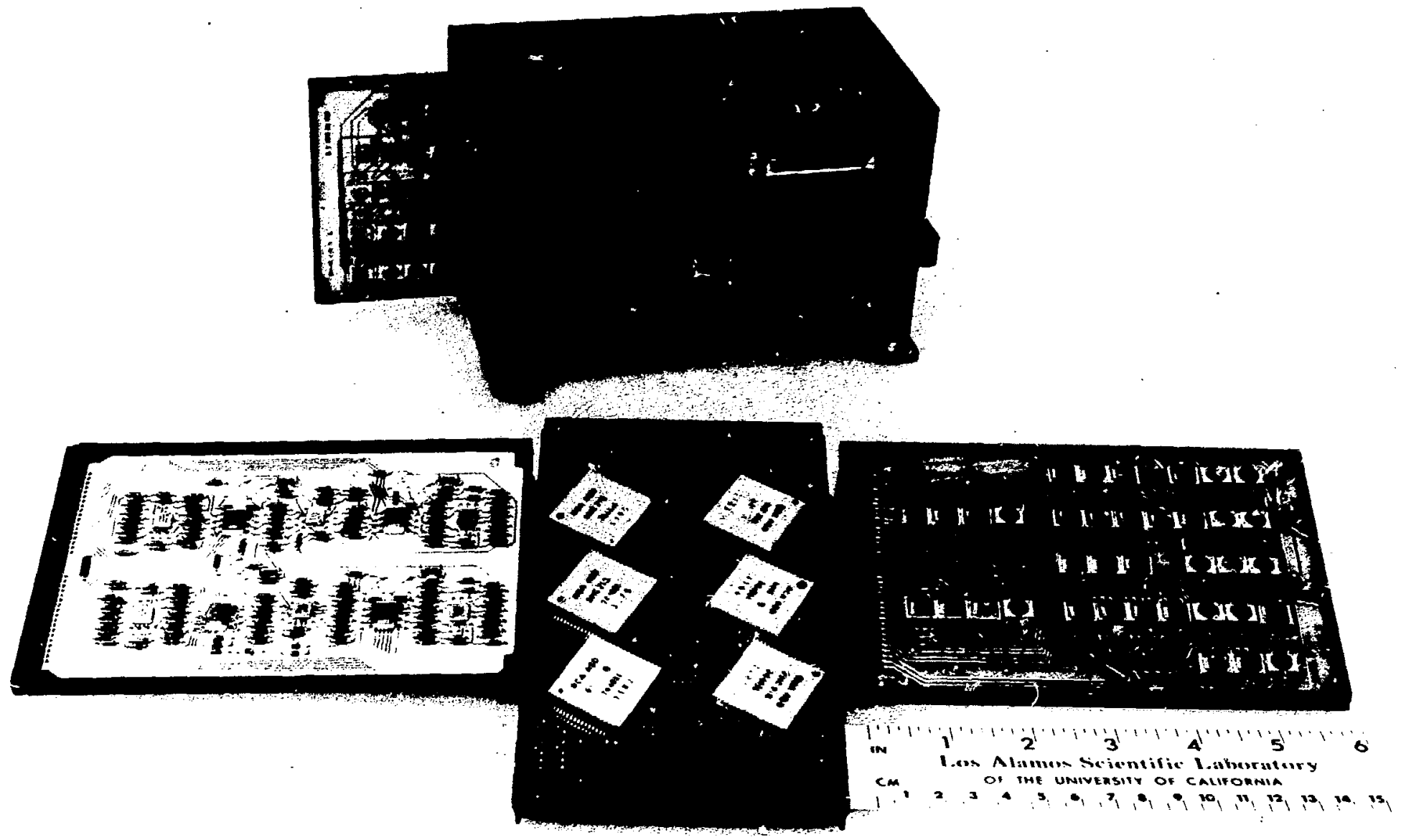

Fig. 5.

LASL flight instrument package. 
and other tower experimenters resulted in an acceptable arrangement by interchanging the location of two experiments and mounting the LASL memory box at the base of the tower. Because this location is a very cold region being shaded fron the sur by the solar cell skirt and almost completely decoupled thermally from the main equipment compartment, a modification of the tower base structure was made to allow the LASL package to view the main equipment compartment.

\section{PROJECT MANAGEMENT AND DATA ANALYSIS}

For purposes of project control (interface drawings, testing procedures, scheduling, design reviews, and so on), the LASL memory package is viewed by the Project Office as a component of the SSL Solar X-Ray Experiment instrument. The analysis of solar $x$-ray data will remain the responsibility of SSL while analysis of cosaic gamma ray data will be the responsibility of LASL. For simplicity and convenience, it has been proposed that a separate data tape containing specifically the gama-ray data be furnished by the Project office to LASL.

Since the cosmic gamma-ray experiment for the ISEE-C Heliocentric spacecraft is primarily intended to serve as one element in a network of several such detector systems, it has been proposed that a system be devised for rapid comparison of results. However the method for accomplishing this is, at present, undefined. It is the intent that the results from this experiment be immediately available for mutual comparison with results from other defector systems in the network. The ISEE-C Heliocentric spacecraft is currently scheduled for launch from the Eastern Test Range at Cape Canaveral, Florida in June or July of 1978.

\section{ACKROWLEDGMENTS}

The authors wish to thank L. K. Cope of Group P-4 for the initial construction and testing of the breadboard circuitry. Thanks are also extended to W. S. Workman of Group P-4 who performed the final tests on the breadboard as well as the flight unit and who was involved in the construction and testing of the Ground Support Equipment. We e..tend our appreciation to L. Anderson and L. Osmond of Sandia Laboratories, Albuquerque (SLA), who were responsible for 
supervising the rinal layout and construction of the ten multilayer electronics boards used in flight unit. Our thanks also to G. Peterson (SLA) for the mechanical design of the flight package and to E. C. Hittwer (SLA) for supervising the construetion of the unit.

\section{REFERENCES}

1. R. W. Klebesadel, I. B. Strong, and R. A. Olson, nobservations of Gamma-Ray Bursts of Cosmic Origin," Astrophys. J. Lett. .32, L85-L88 (1973).

2. T. L. Cline, U. D. Desa1, R. W. Klebesadel, and I. B. Strong, "Energy Spectra of Cosnic Gama-Ray Bursts, Astrophys. J. Lett. 185, L1-L5 (1973).

3. W. A. Wheaton, M. P. Ulmer, W. A. Baity, D. W. Datlow, M. J. Elcan, L. E. Peterson, R. W. Klebesadel, I. B. Strong, T L. Cline, and U. D. Desa1, "The Direction and Spectral Variability of a Cosmic Gamma-Ray. Burst," Astrophys. J. Lett. L57-L61 (1973). 


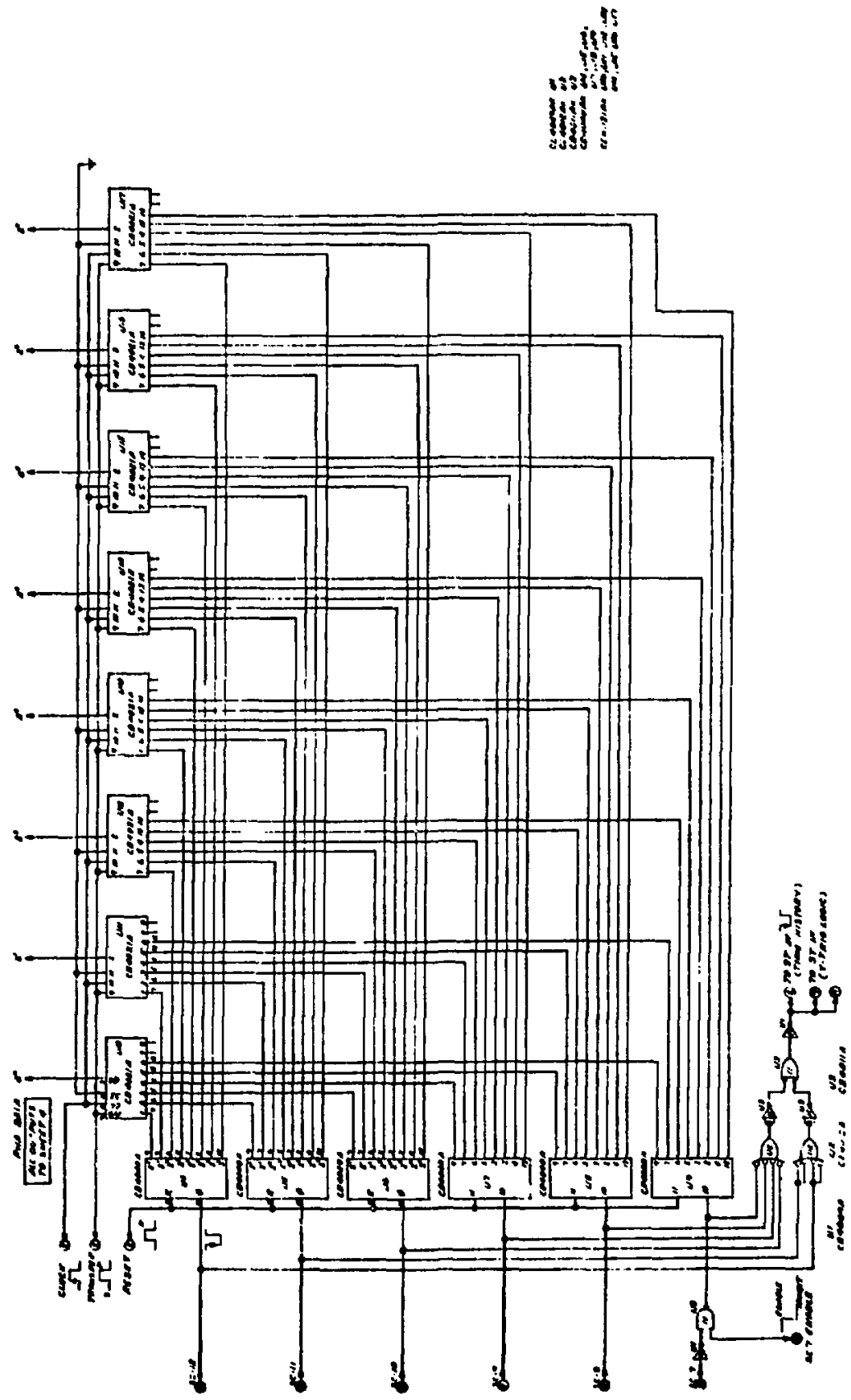

岁 


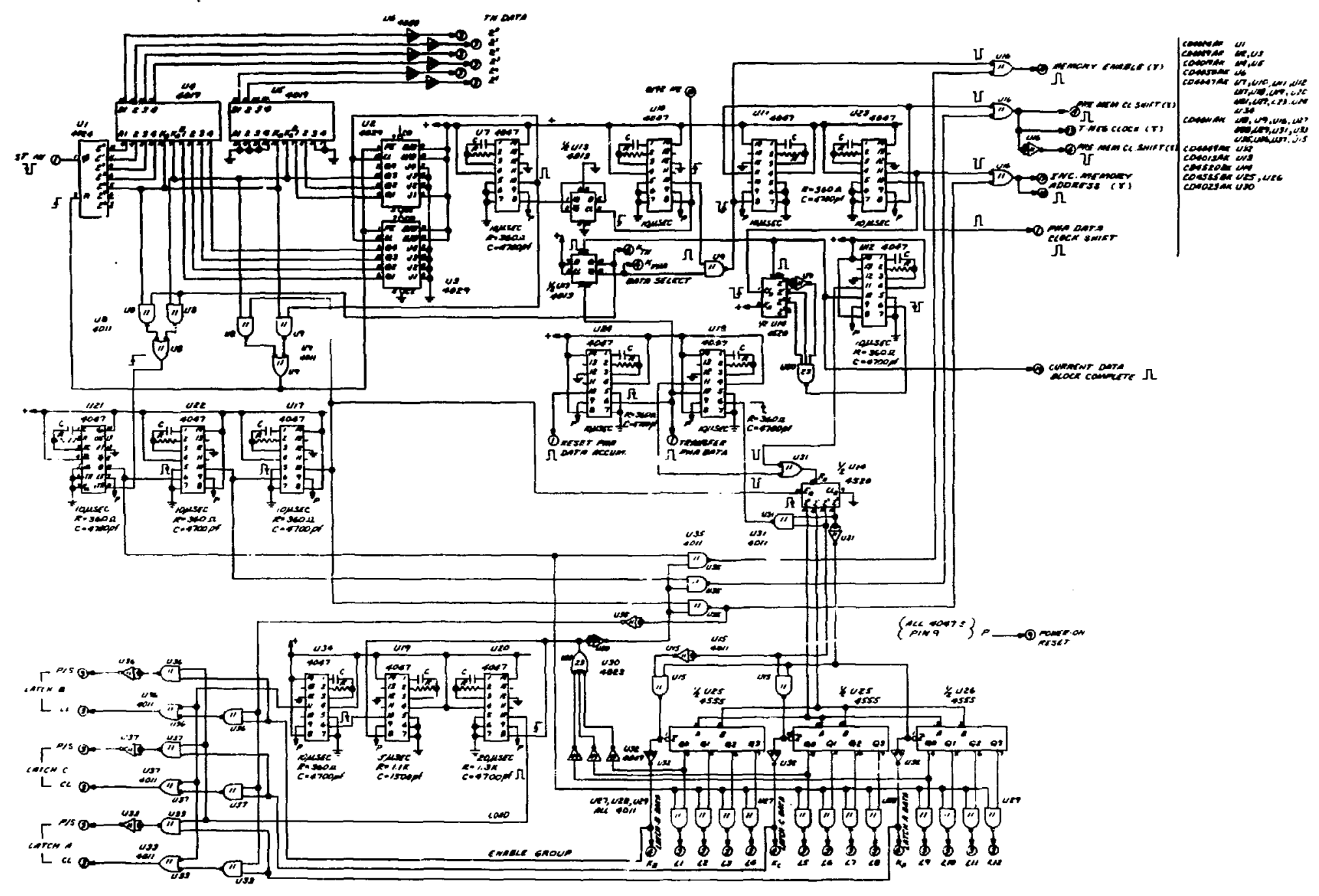

Fig. A-2. Time history and PHA data handling and timing logic. 


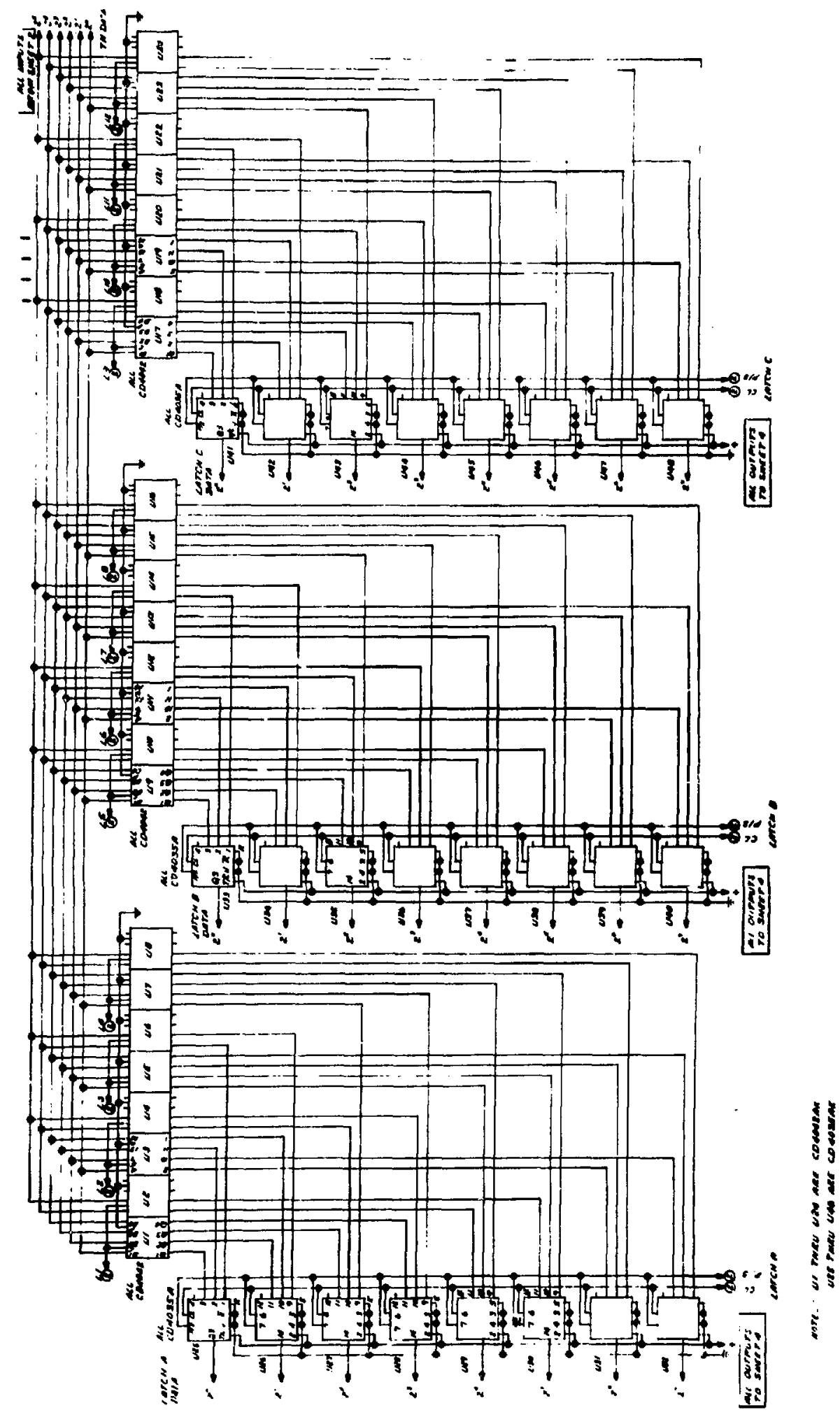

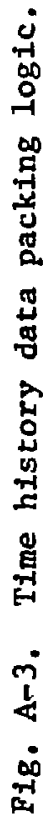

3

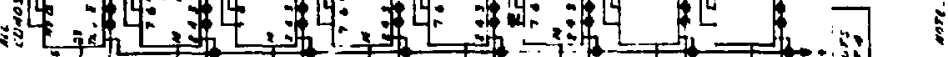

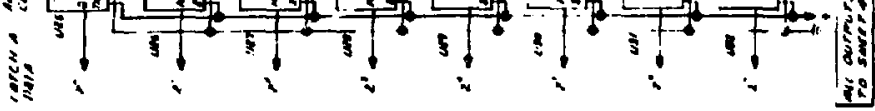




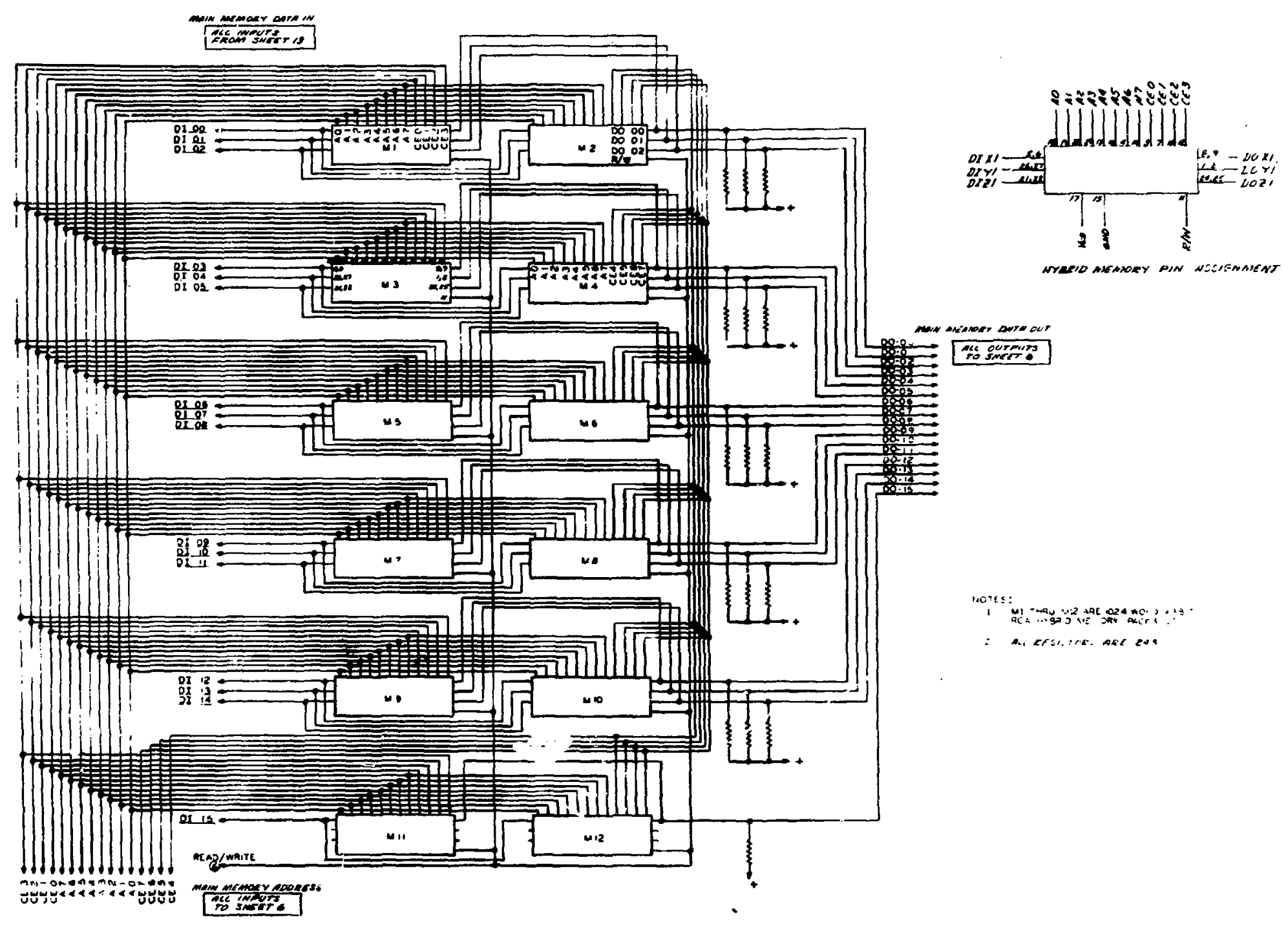

Fig, A-4, Schematic of the 2048-x 16-bit main memory. 


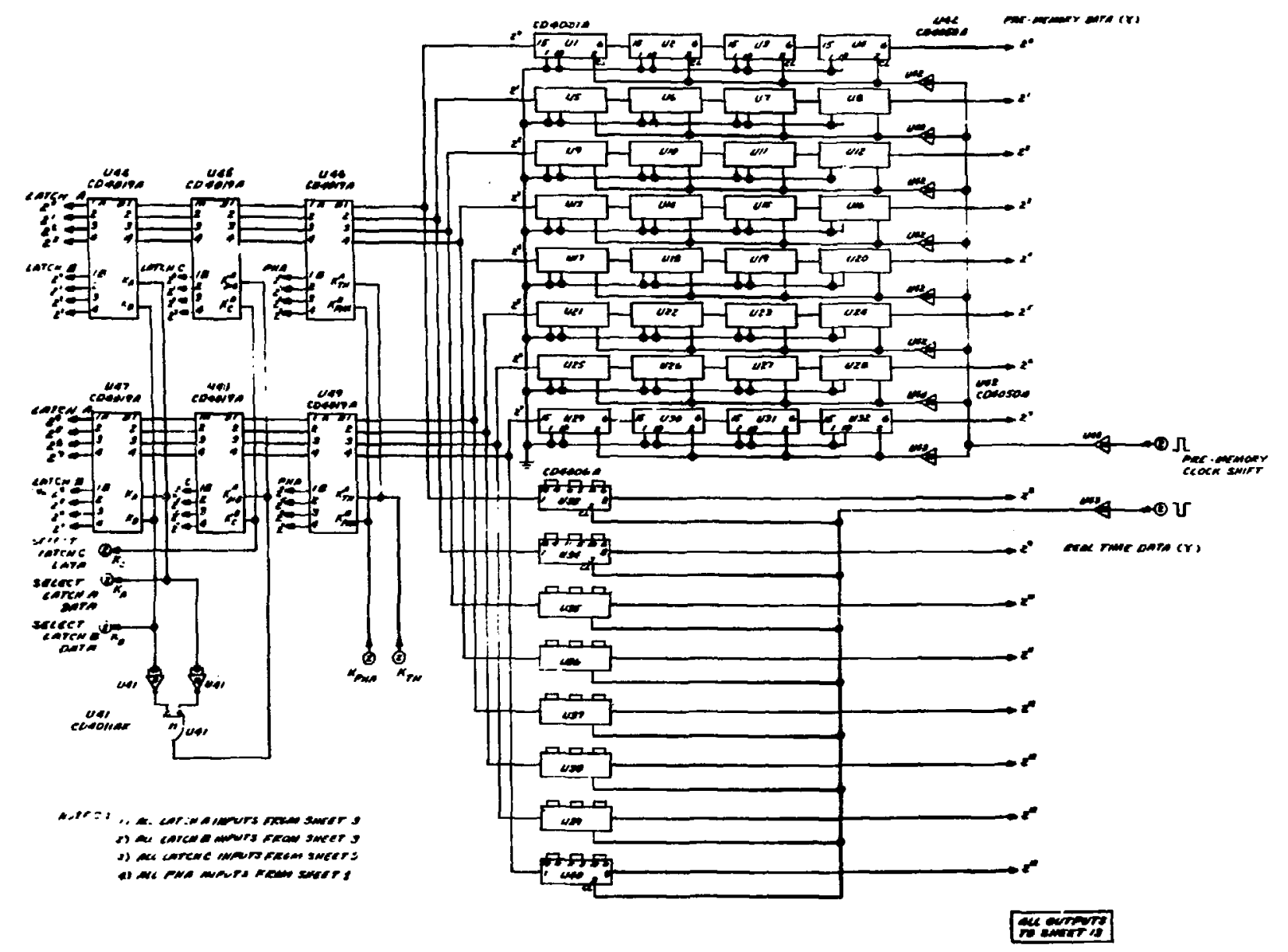




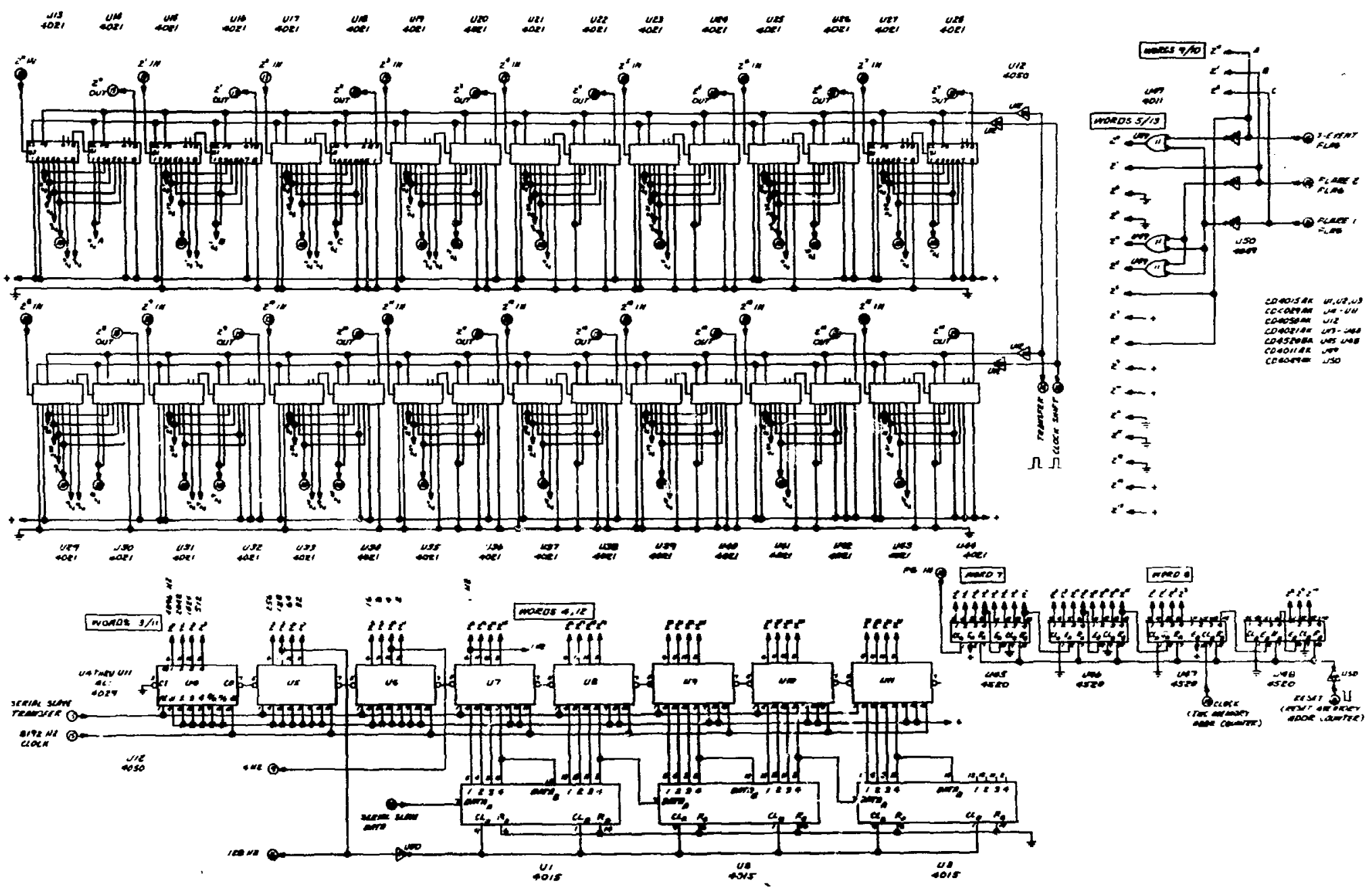

Fig. A-6, The T-register. 


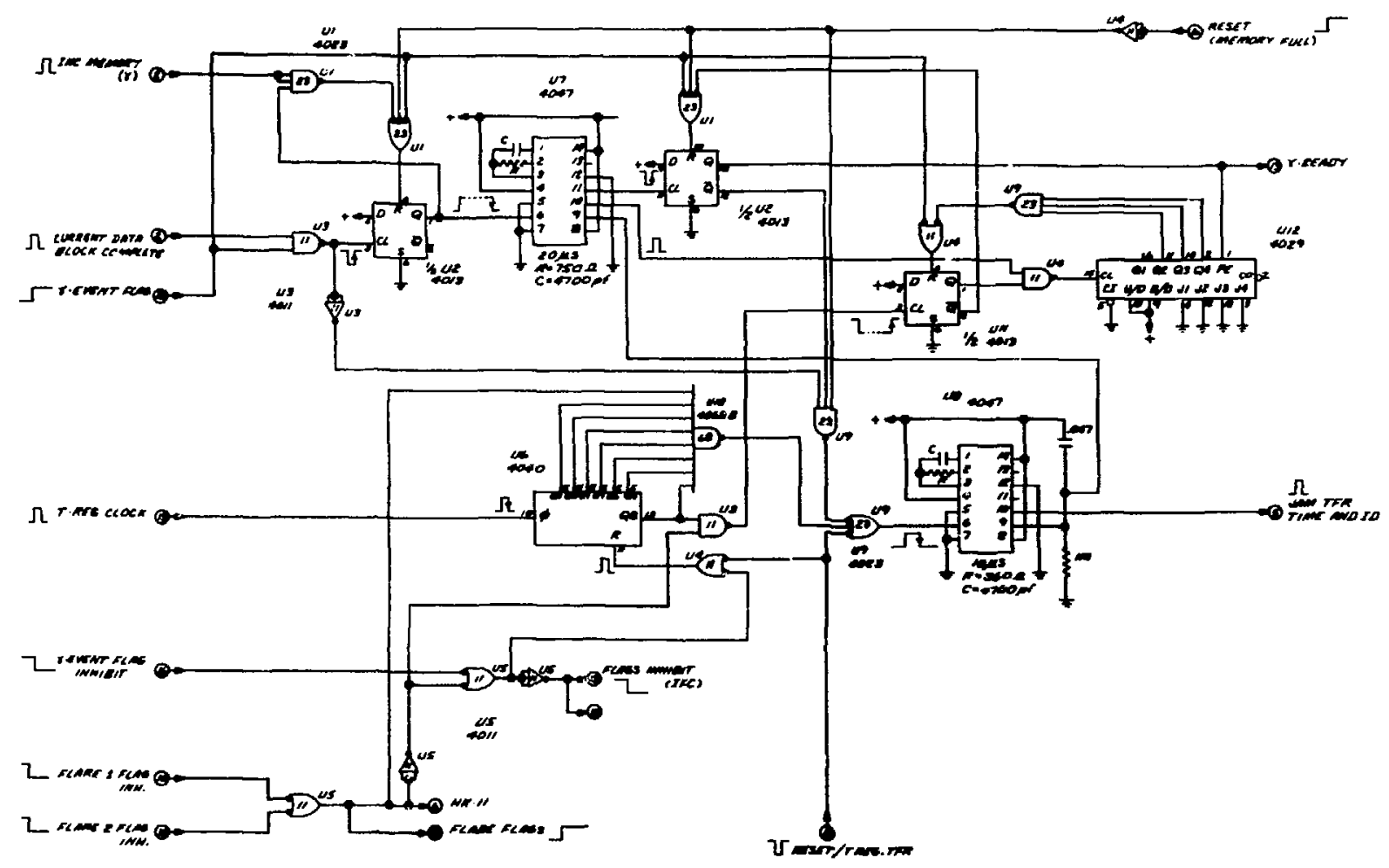




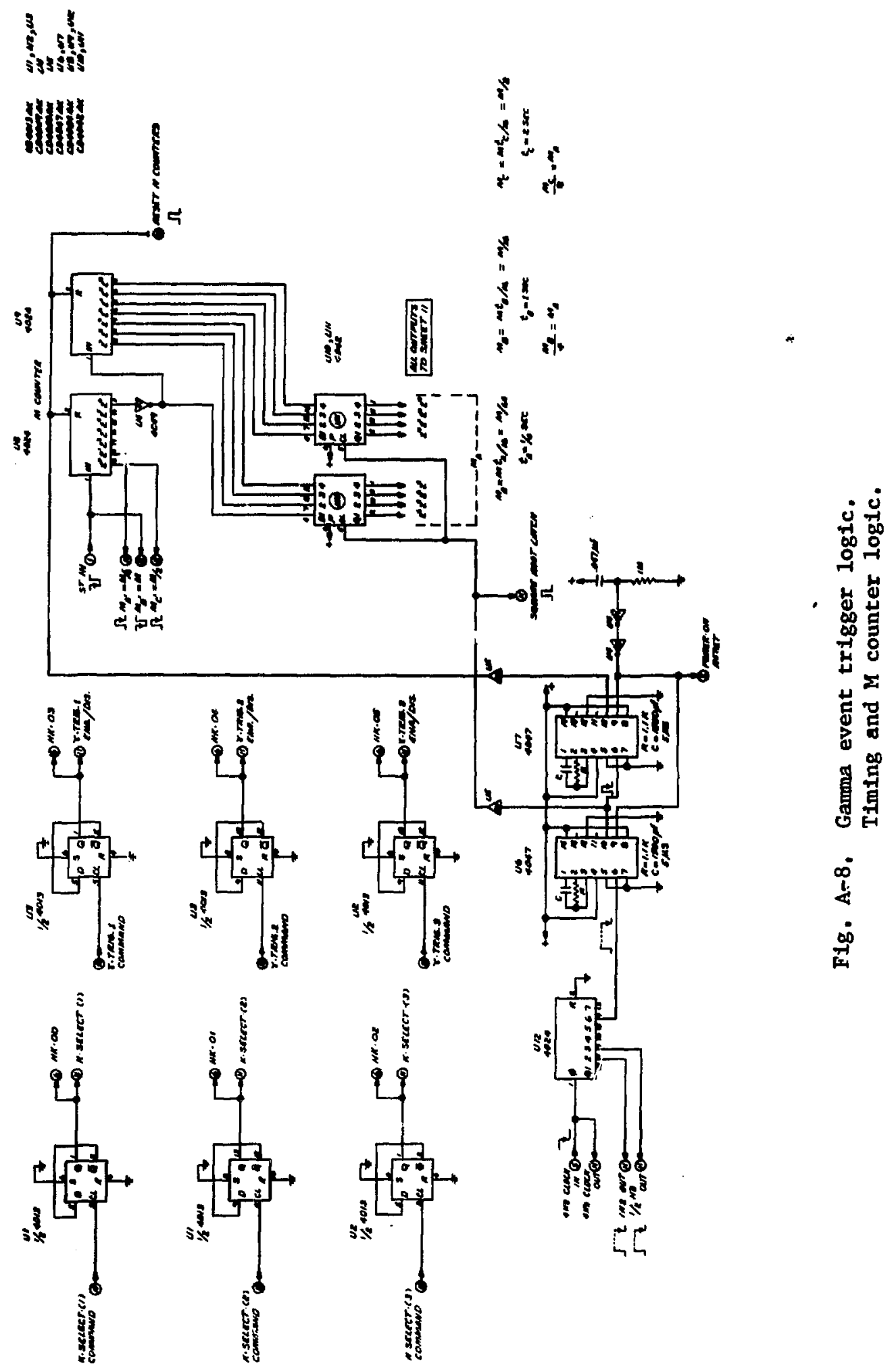




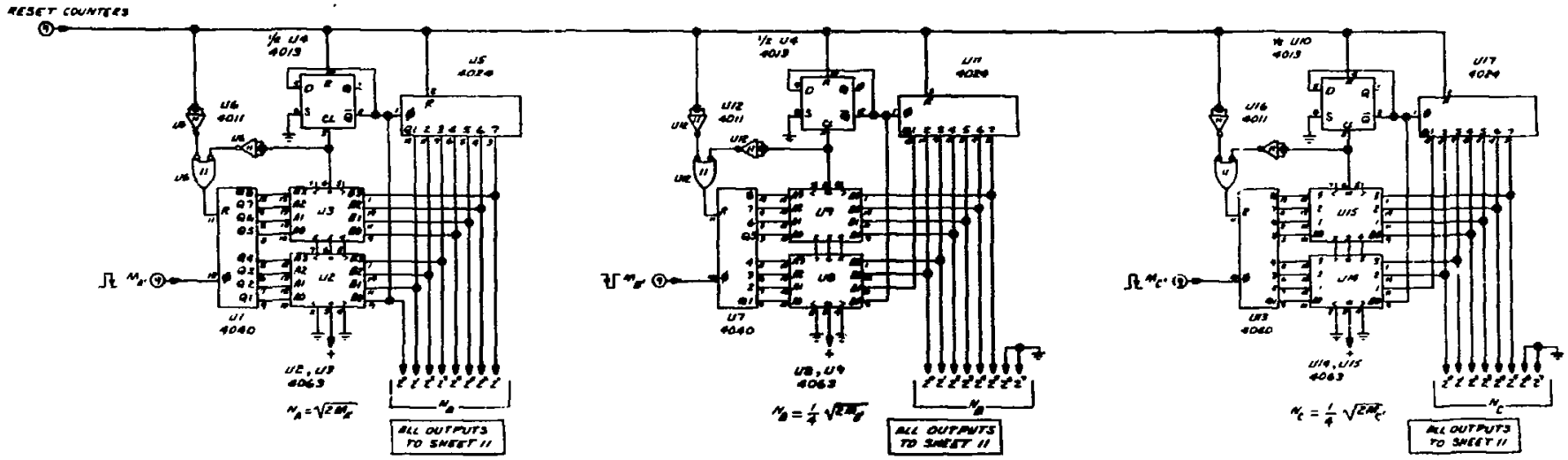


岕

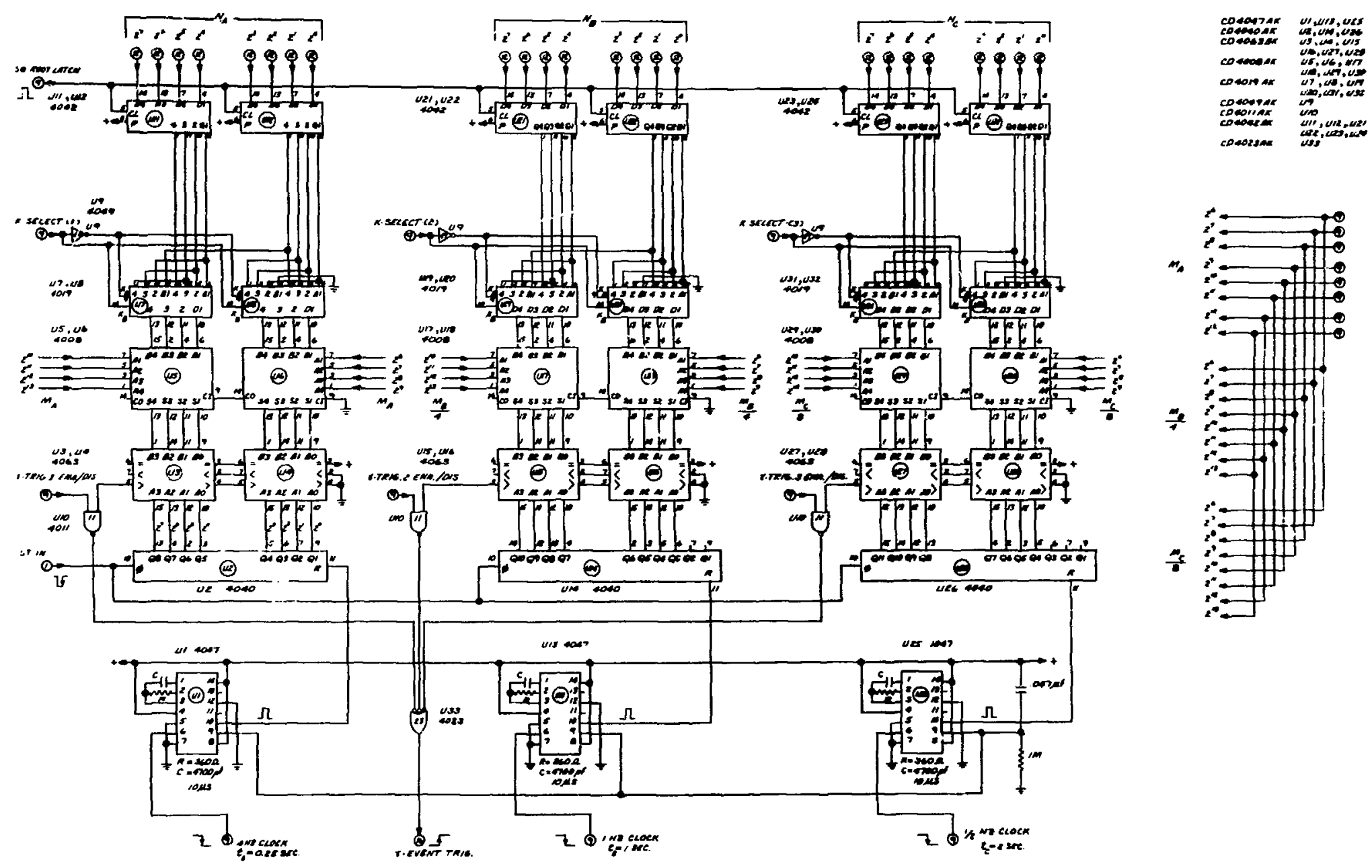

F1g. A-10, Gamma event trigger $\log i c$. Comparator logic. 


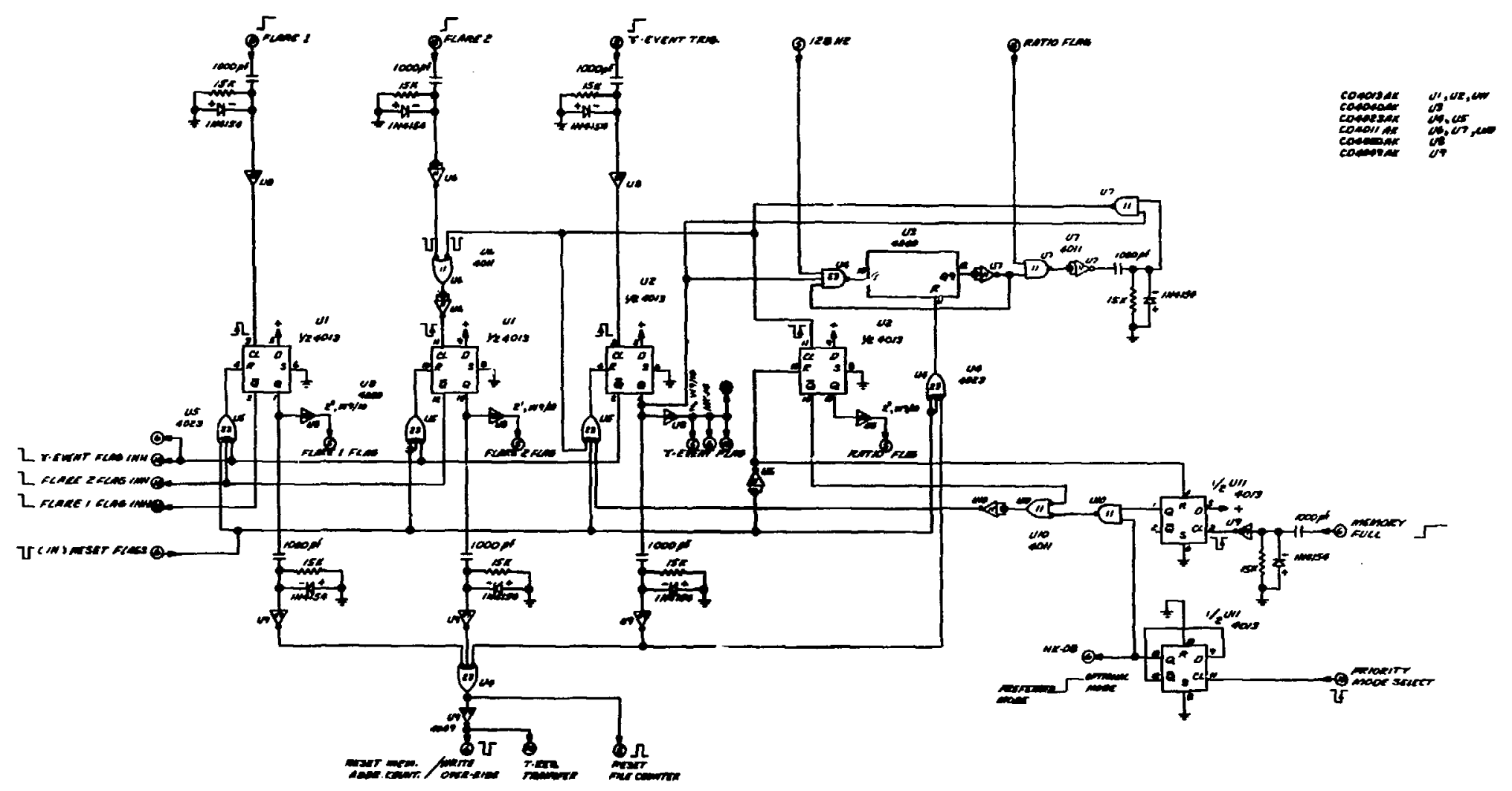

Fig. A-1l. Automatic priority logic. 
岕

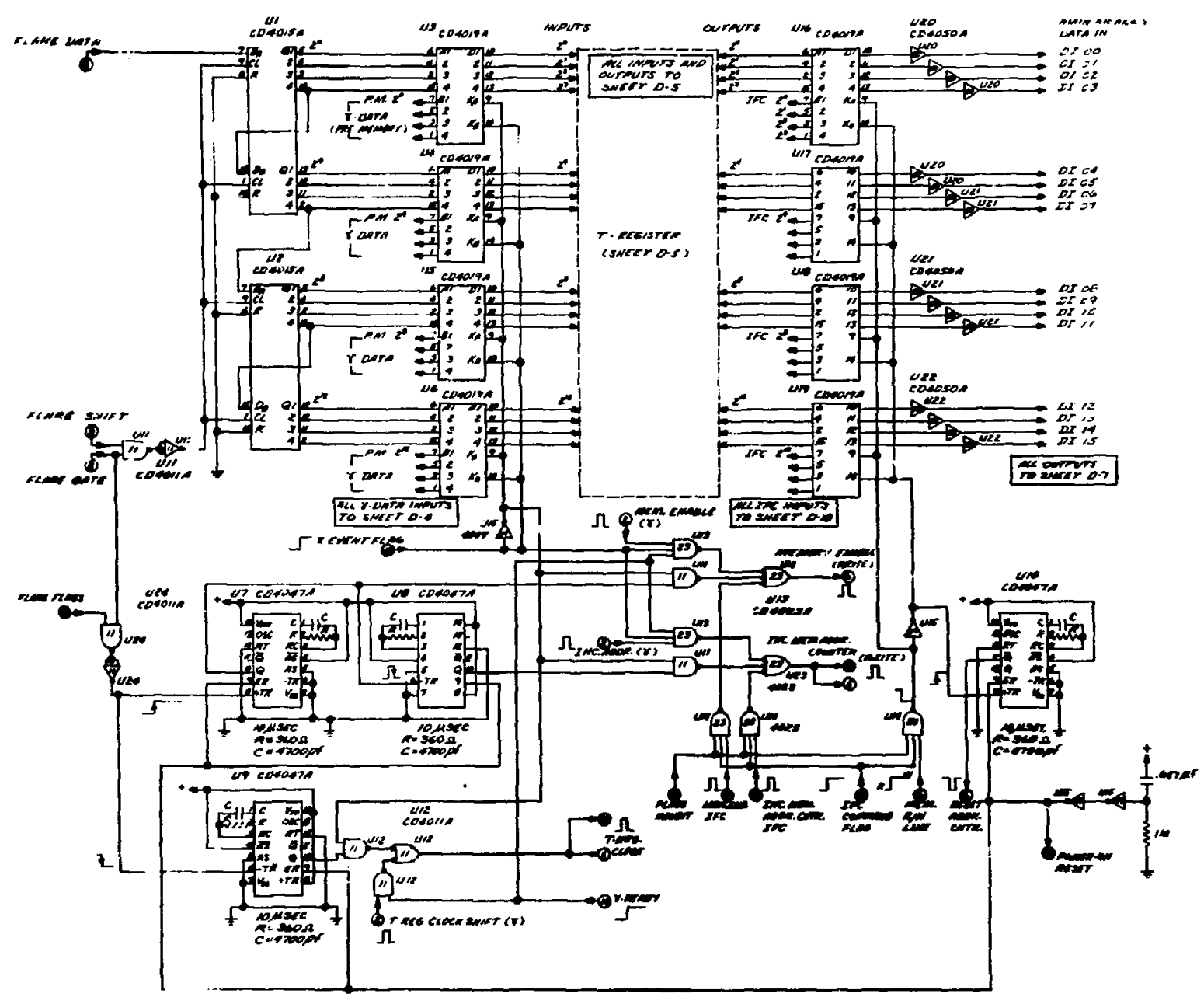

F18. A-12, Flare data sertal Interface and data merge. 


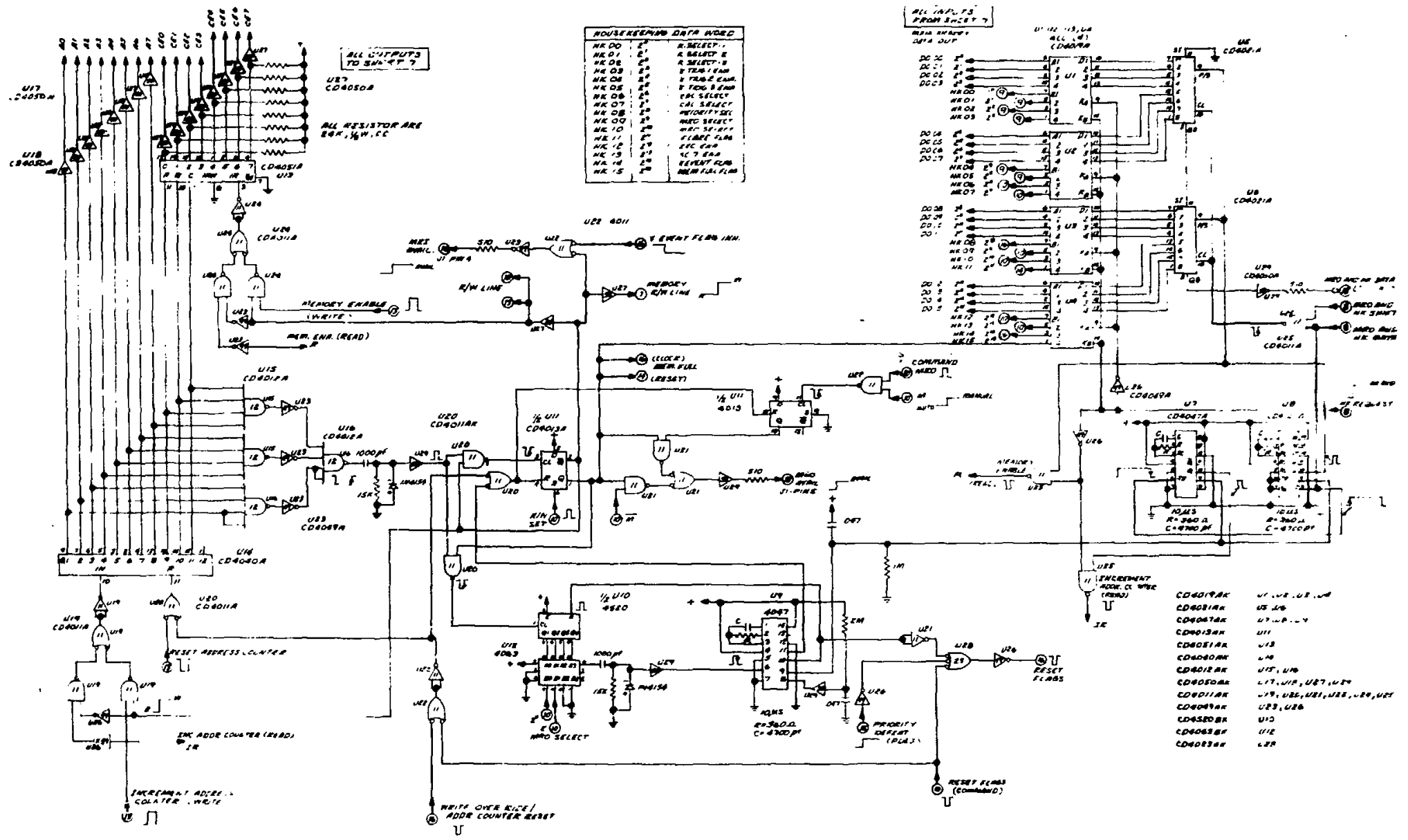




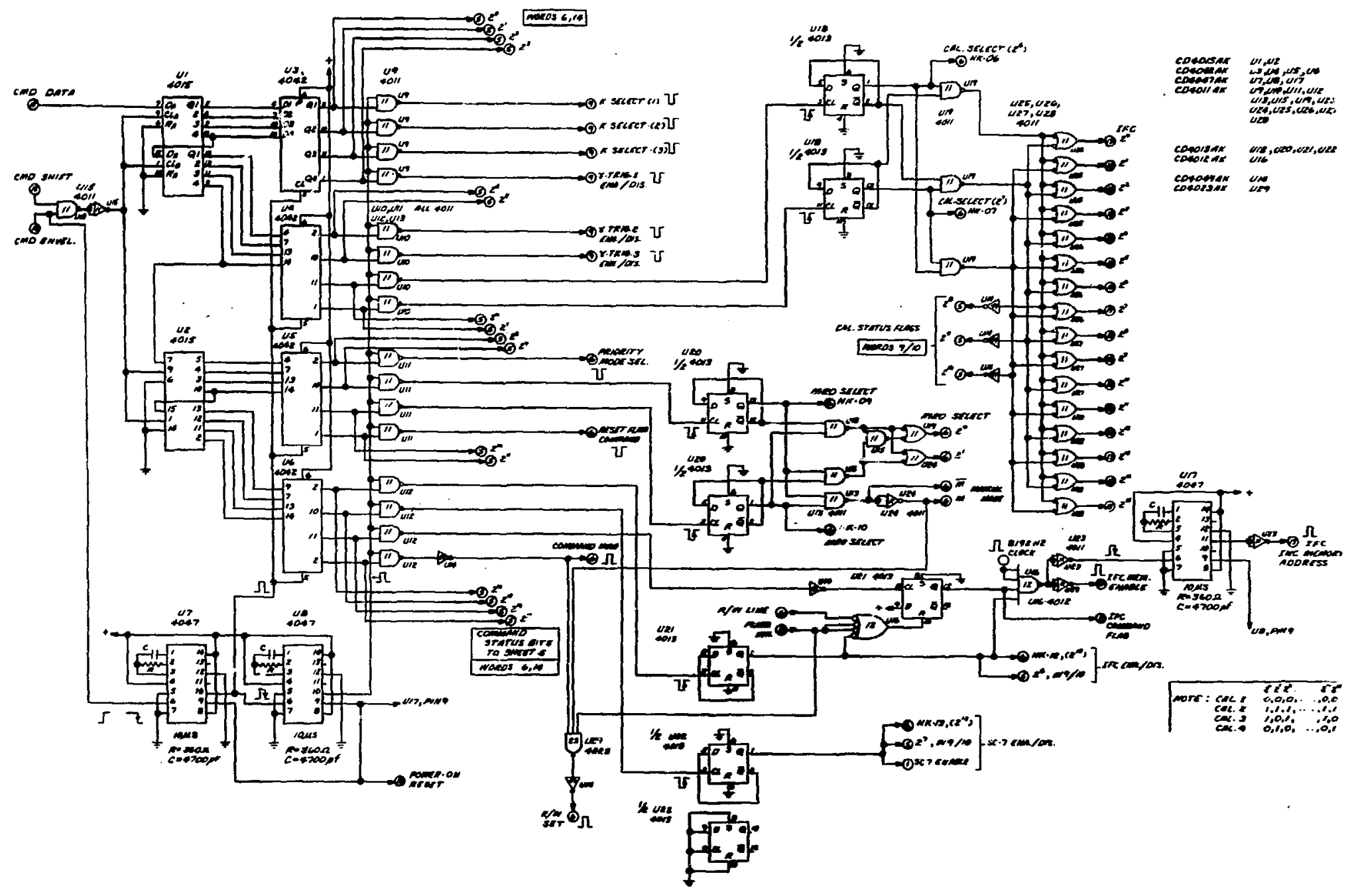

Fig. A-14. Serial comnand interface logic. 

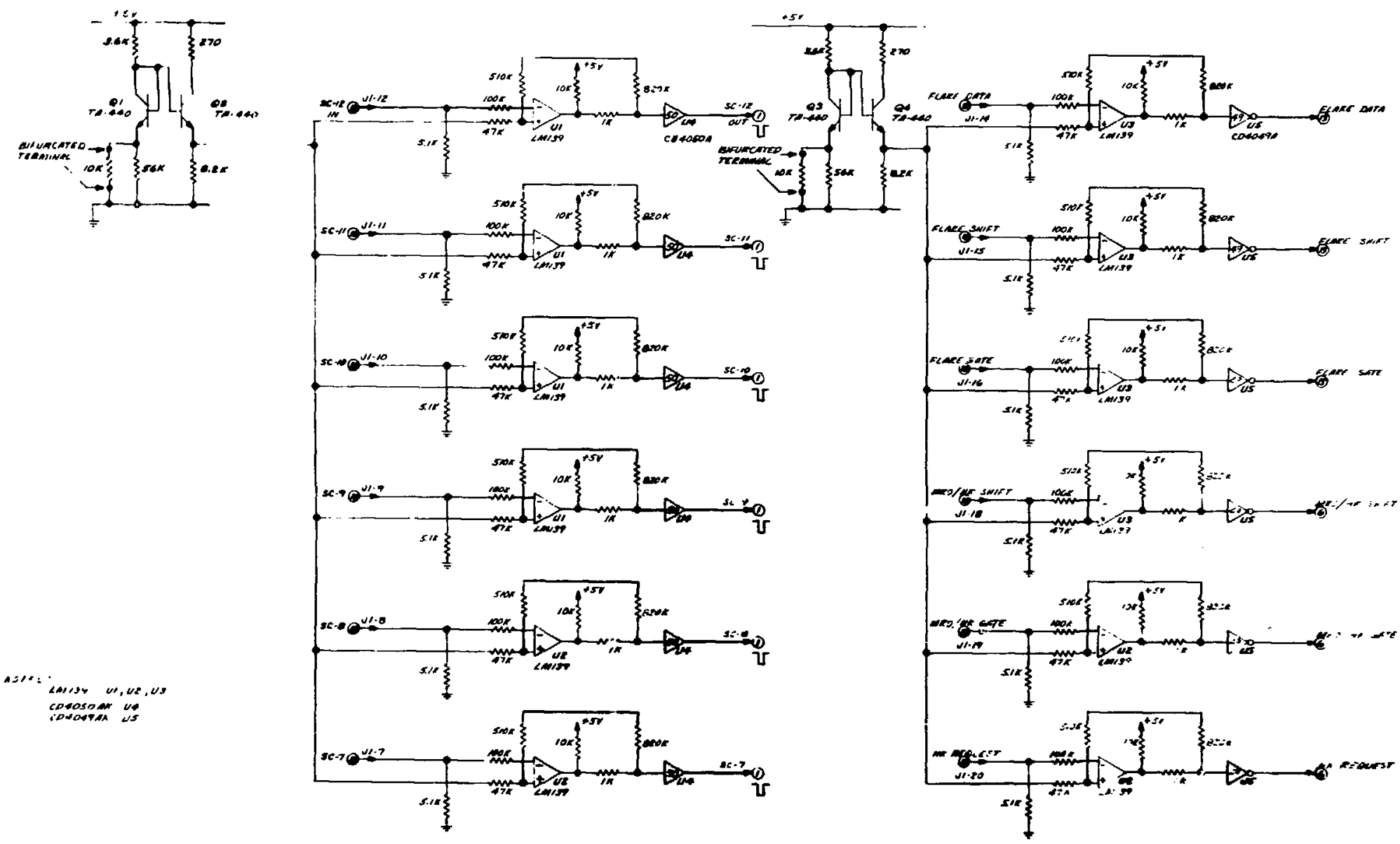


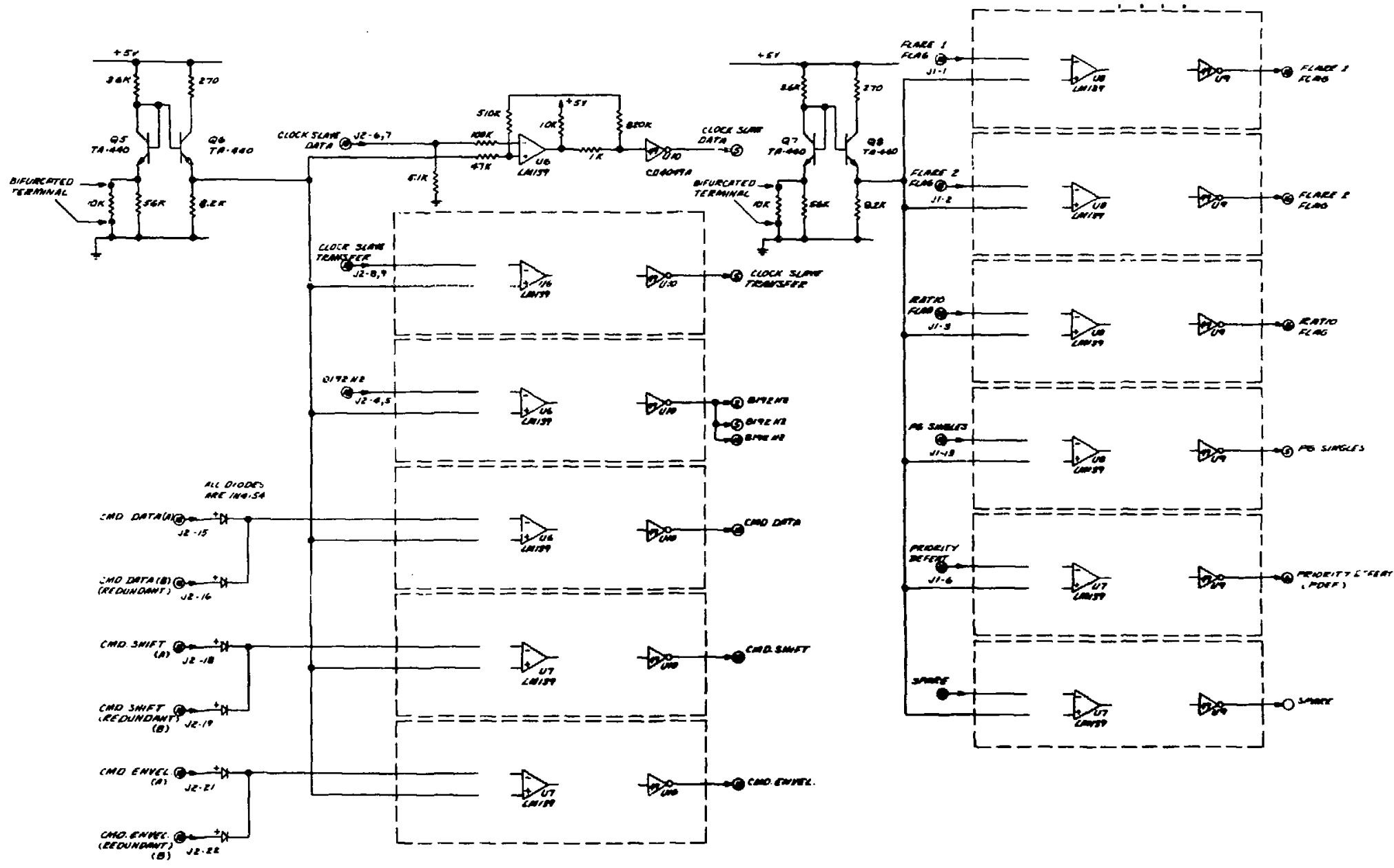

Fig. A-16. LASL/spacecraft and LASL/SSL interface circults. 
TI TL AER YSI PECCISION THCEMISTOES,

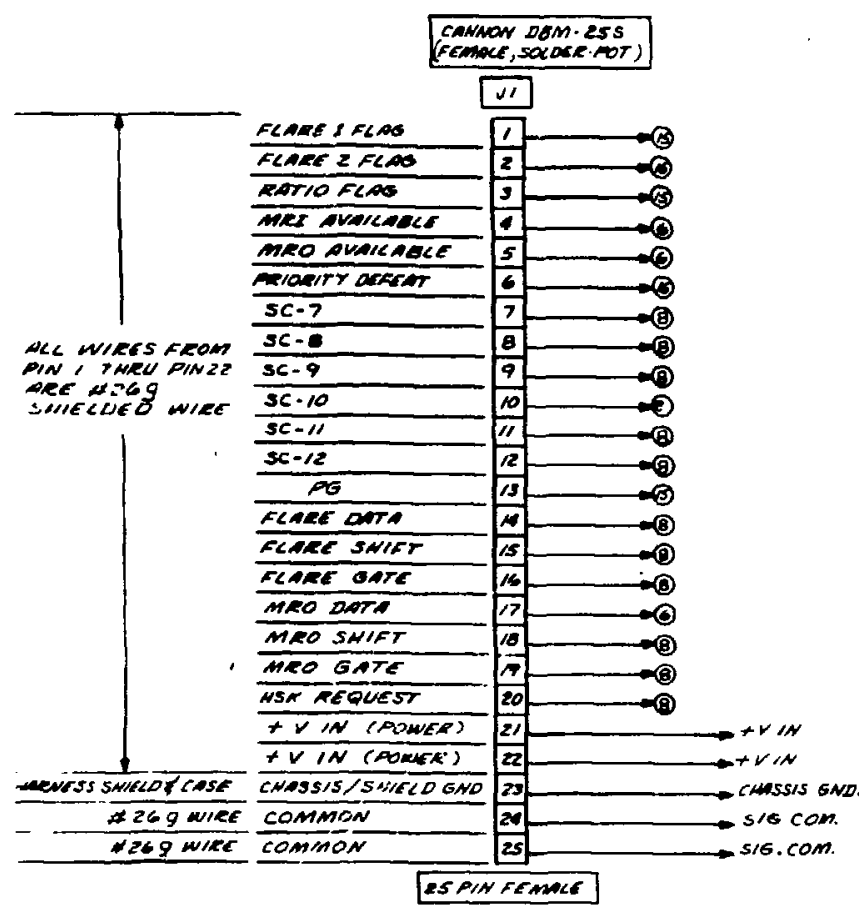

X.ReY inNor

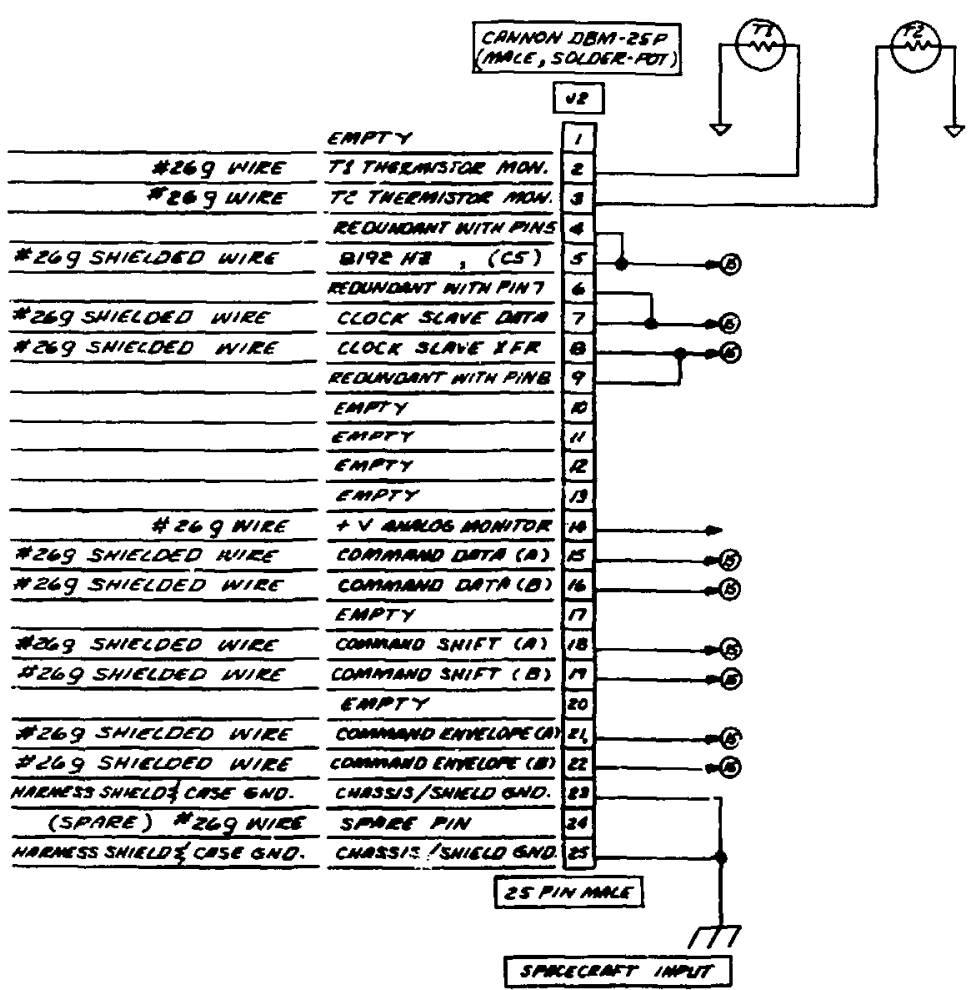

SAmcecent inayt

\footnotetext{
NoTES

2.) CASE GeOUND तh

s.) SIGNAC COMMON b
}

1.) IN OROER TO AVOIO ERROR, JI IS FEMULe 
TABLE B-I

T-REGISTER BIT DESCRIPTION

Oeral t-212 Hord

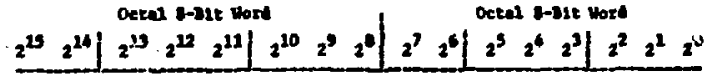

$$
\text { . }
$$



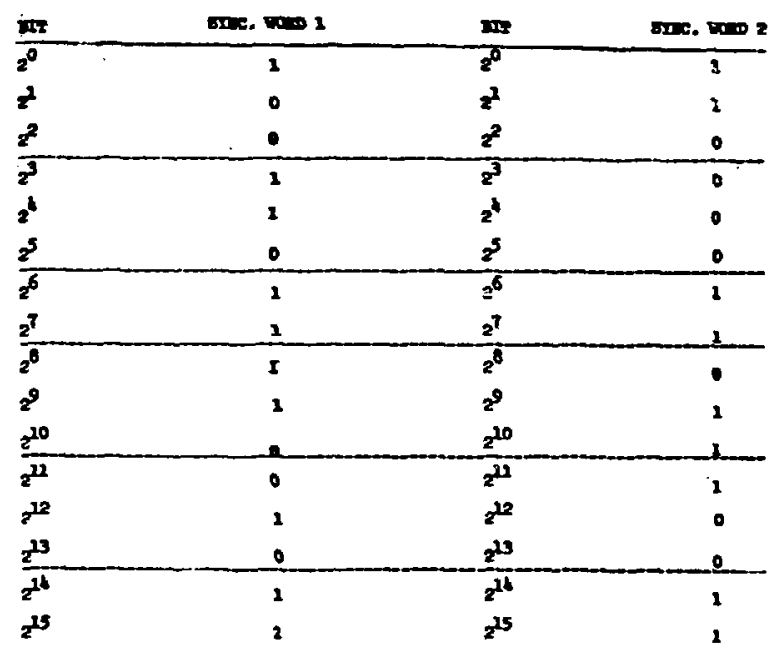


TABLE B-III

T-REGISTER WORDS 3 AND 11

Comend Register Status

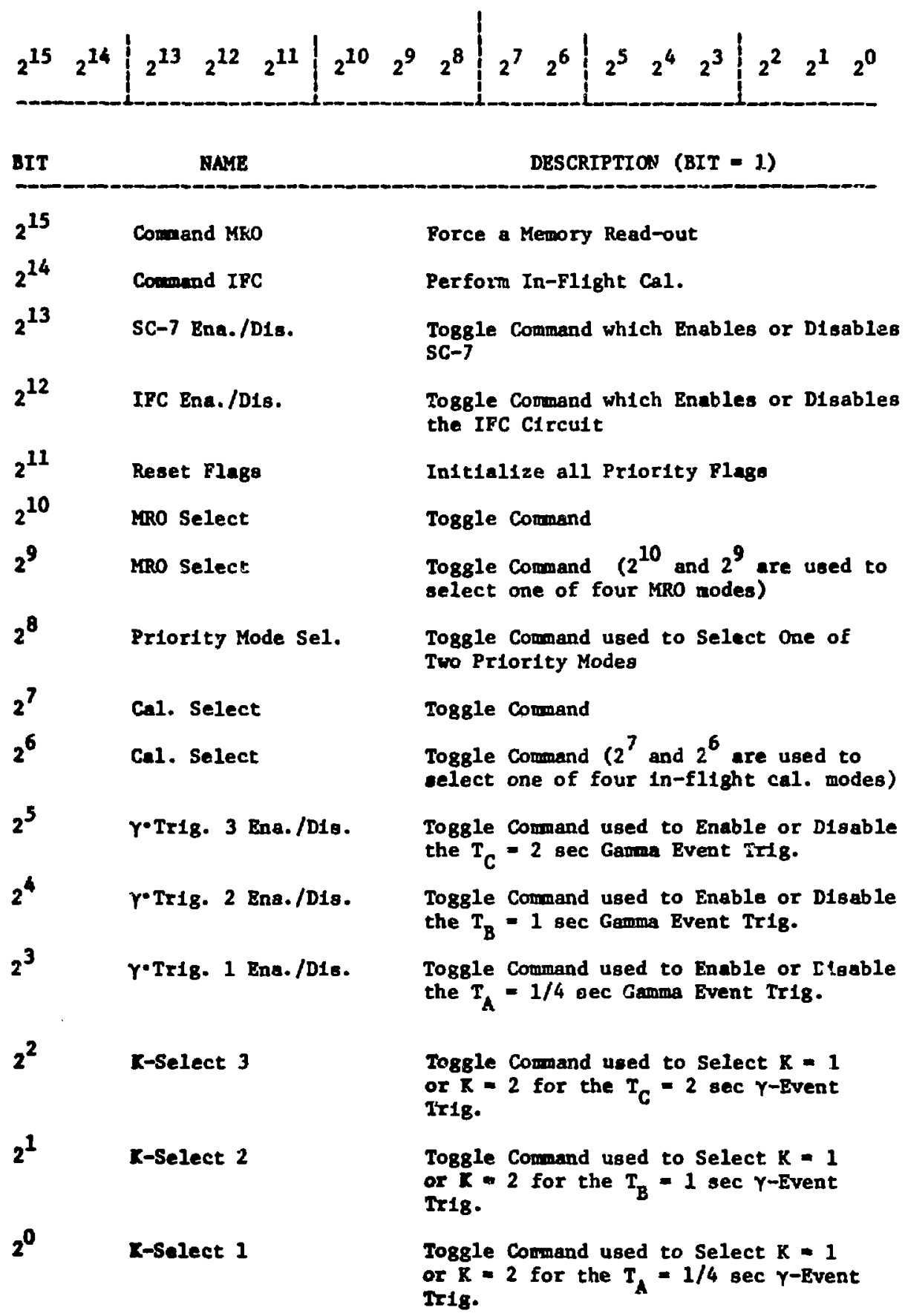


TABLE B-IV

\section{T-REGISTER WORDS 3 AND 11}

Comind Reglater statue

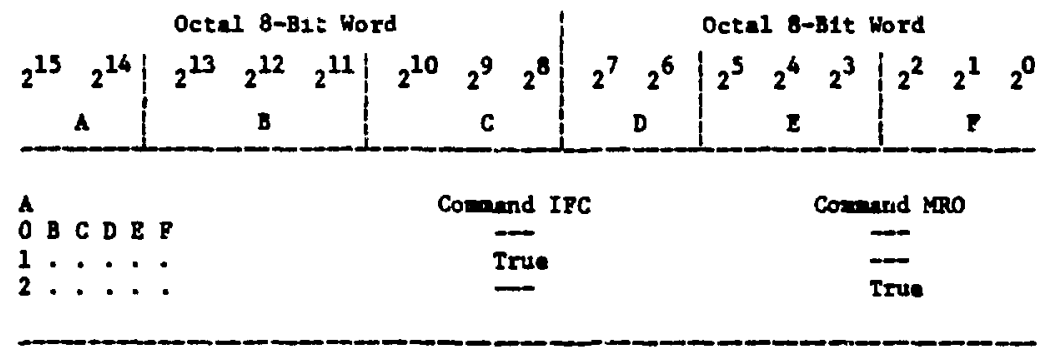

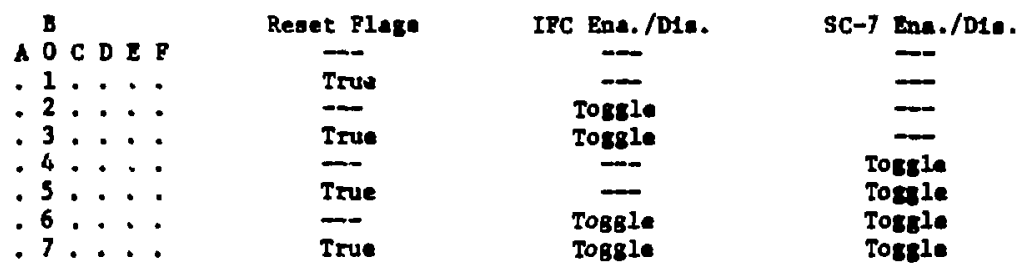

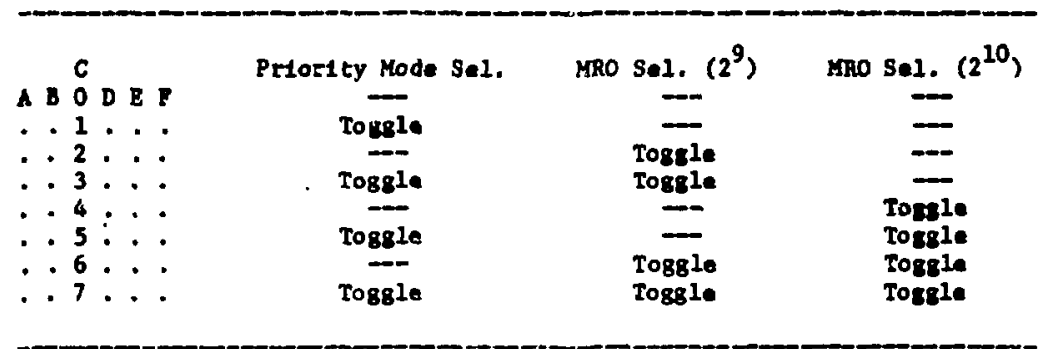
A B C O E F
-. 1 ..
.. 2 ..
.. 3 .
Cal. Sel. $\left(2^{6}\right)$
Cal. Sel. $\left(2^{7}\right)$
Togsle
rogele
Togsle
Toggla

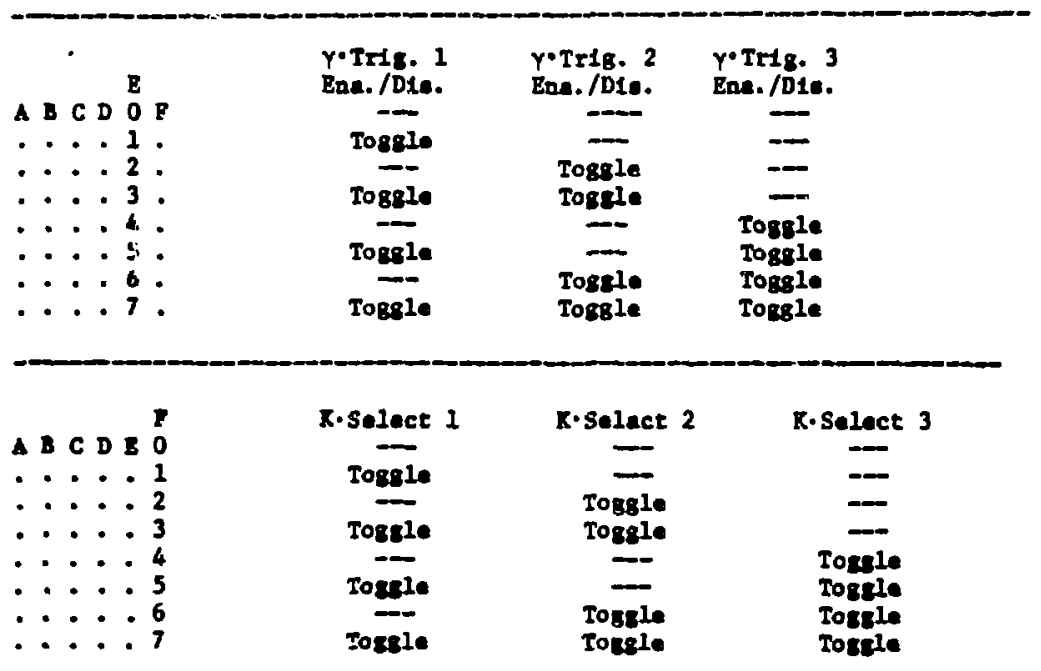




\section{TABLE B-V}

T-REG. WORD 4

(RFPEATED IN WORD 12)

MFAORY DATA IDENT. (ID)

\begin{tabular}{lcccc} 
BIT & $\gamma \cdot$ EVENT & BLARE 2 & FLARE 1 \\
\hline $2^{0}$ & 1 & 0 & 1
\end{tabular}

$2^{1}$

0

1

0

$2^{2}$

0

0

0

$2^{3}$

0

0

o

$2^{4}$

0

1

1

$2^{5}$

0

2

0

1

0

0

$2^{7}$

1

1

1

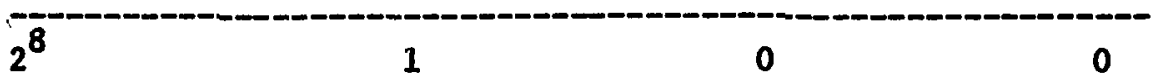

$2^{9}$

1

1

1

$2^{10}$

1

$2^{11}$

0

1

1

$2^{12}$

0

0

0

$2^{13}$

$2^{14}$

1

0

0

$2^{15}$

1

1

1 
TABLE B-VI

\section{T-BEGISTER WORD 7}

(REPEATED IN WORD 8)

maces status wORD

215
$2^{0}$
$2^{1}$
$2^{2}$
$2^{3}$
$2^{4}$
$2^{5}$
$2^{6}$
$2^{7}$
$2^{8}$
$2^{9}$
$2^{10}$
$2^{11}$
$2^{12}$
$2^{13}$
$2^{14}$
$2^{15}$

RATIO FLAG

Cal. status

\section{DESCRIPT:ON}

GAYMA EVEST FLAG

TLARE 2 TLAC

pLARE 1 RAaG

(ROT ASSIGNBD)

(MOT ASSIGAED)

IFC ENA./DIS. THAG

SC-7 ENA./DIS. FLAG

CAL. STATUS

CAL. States

\begin{tabular}{|l|l|l|l|}
\hline $2^{10}$ & $2^{9}$ & $2^{8}$ & \\
\hline 0 & 0 & 0 & CAL. 1 \\
\hline 0 & 0 & 2 & CAL.2 \\
\hline 0 & 1 & 0 & CAL. 3 \\
\hline 1 & 0 & 0 & CAL. 4 \\
\hline
\end{tabular}

(MOT ASSIGNED)

(HOT ASSICNED)

(nOT ASsTGNed)

(HOT ASSICNED)

(nOT ASSTGNED)
TABLE B-VII

\section{T-REGISTER WORDS 7 AND 8}

Flags Status

$2^{15} 2^{14}$
0

\begin{tabular}{|c|c|c|}
\hline 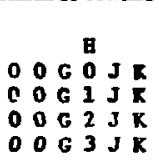 & $\begin{array}{l}\text { (26) IFC Ene./OLs. } \\
\text { Dianbled } \\
\text { Enabled } \\
\text { Disabled } \\
\text { Enabled }\end{array}$ & $\begin{array}{l}\left(2^{7}\right) \text { SC-7 Inn. /DA. } \\
\text { DHarbled } \\
\text { Disabled } \\
\text { Enubled } \\
\text { Envibled }\end{array}$ \\
\hline 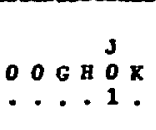 & $\begin{array}{c}\left(2^{3}\right) \text { Ratio Plas } \\
\text { No } \\
\text { Tea }\end{array}$ & $\begin{array}{c}\left(2^{4}, 2^{5}\right) \\
0,0\end{array}$ \\
\hline
\end{tabular}

\section{r}

Gamma Event Flag $\left(2^{0}\right)$ plare 2 Flag $\left(2^{2}\right)$ Flare 1 Flag $\left(2^{2}\right)$

\begin{tabular}{|c|c|c|}
\hline 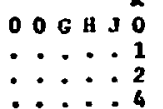 & $\begin{array}{r}\text { No } \\
\text { Yes } \\
\text { No } \\
\text { Ho }\end{array}$ & $\begin{array}{r}\text { Fo } \\
\text { No } \\
\text { Yes } \\
\text { Eo }\end{array}$ \\
\hline
\end{tabular}

WOTE: Bats not assigned are tied low (comon). 

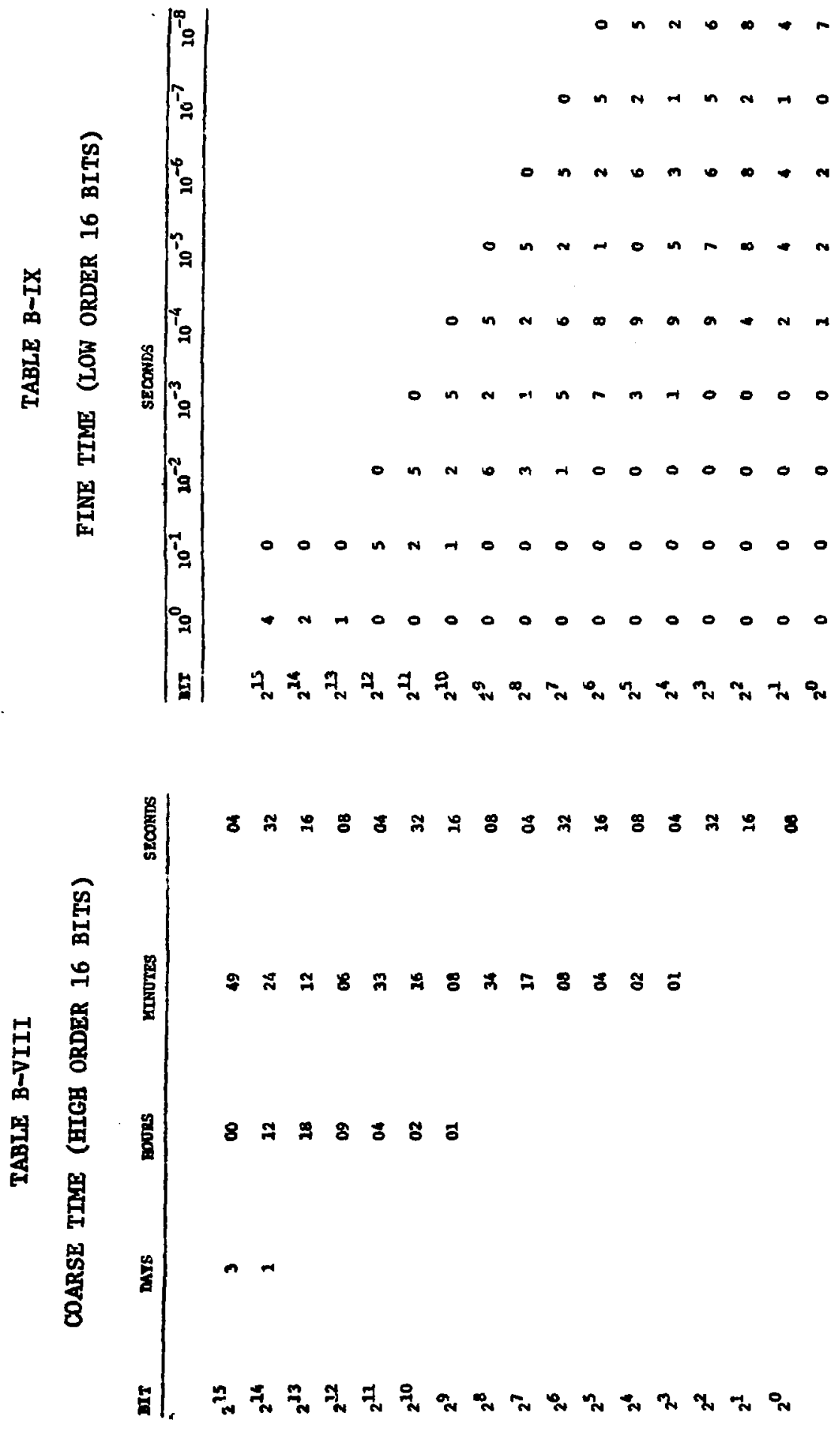
TABLE B-X

T-REGISTER WORDS 9 AND 10

PG ACCUMULATOR

\begin{tabular}{|c|c|c|}
\hline & BIT & COUNTS/SECOND \\
\hline $\begin{array}{l}\text { a } \\
\text { 옹 } \\
\text { 을 }\end{array}$ & $\begin{array}{l}2^{3} \\
2^{2} \\
2^{1} \\
2^{0}\end{array}$ & $\begin{array}{llllll}5 & 2 & 4 & 2 & 8 & 0 \\
2 & 6 & 2 & 1 & 4 & 4 \\
1 & 3 & 1 & 0 & 7 & 2 \\
6 & 5 & 5 & 3 & 6\end{array}$ \\
\hline $\begin{array}{l}\text { 염 } \\
\text { 是 } \\
\text { O }\end{array}$ & $\begin{array}{l}2^{15} \\
2^{14} \\
2^{13} \\
2^{12} \\
2^{11} \\
2^{10} \\
2^{9} \\
2^{8} \\
2^{7} \\
2^{6} \\
2^{5} \\
2^{6} \\
2^{3} \\
2^{2} \\
2^{1} \\
2^{0}\end{array}$ & $\begin{array}{rrrrr}3 & 2 & 7 & 6 & 8 \\
1 & 6 & 3 & 8 & 4 \\
8 & 1 & 9 & 2 \\
4 & 0 & 9 & 6 \\
2 & 0 & 4 & 8 \\
1 & 0 & 2 & 4 \\
5 & 1 & 2 \\
2 & 5 & 6 \\
1 & 2 & 8 \\
& 6 & 4 \\
& 3 & 2 \\
& 1 & 6 \\
& & 8 \\
& & 4 \\
& & 2 \\
& & 1\end{array}$ \\
\hline
\end{tabular}

more: 20 bite peratte a mexime of 1048575 counts; $\left(2^{20}-1\right)$.
TABLE B-XI

\section{T-REGISTER WORD 9}

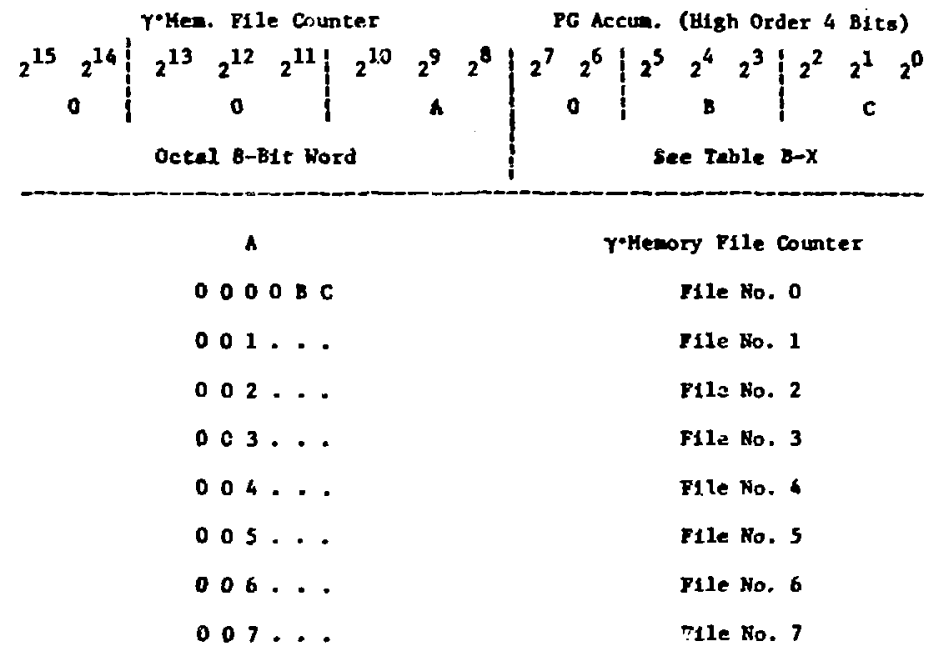




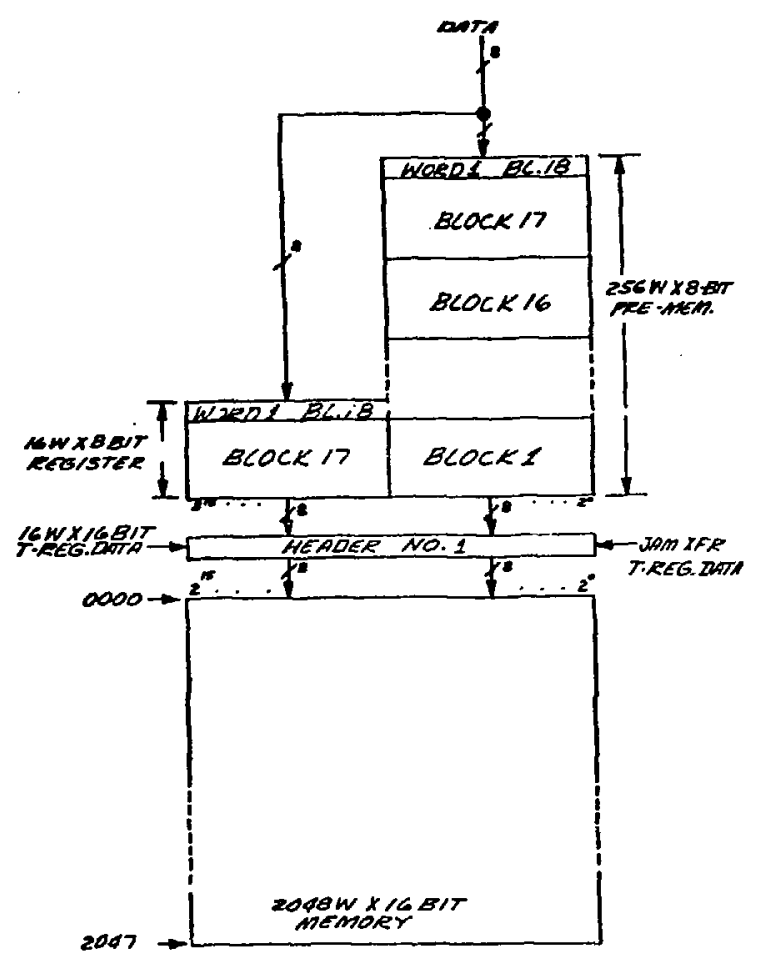

Fig. $C-1$

Memory configuration after a gamma event trigger and just prior to entering data into the main memory.

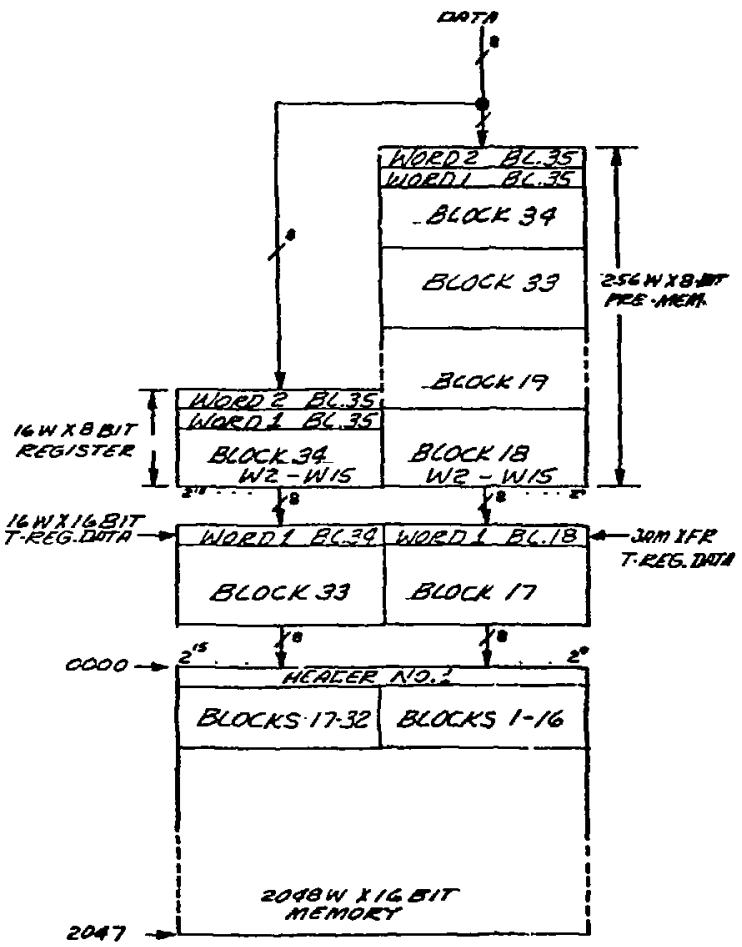

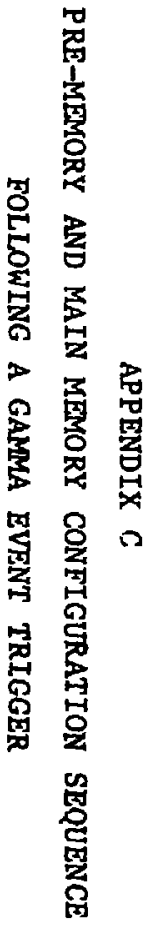

Fig. C-2.

Memory configuration just after transfer of first gamma memory file into the main memory. 


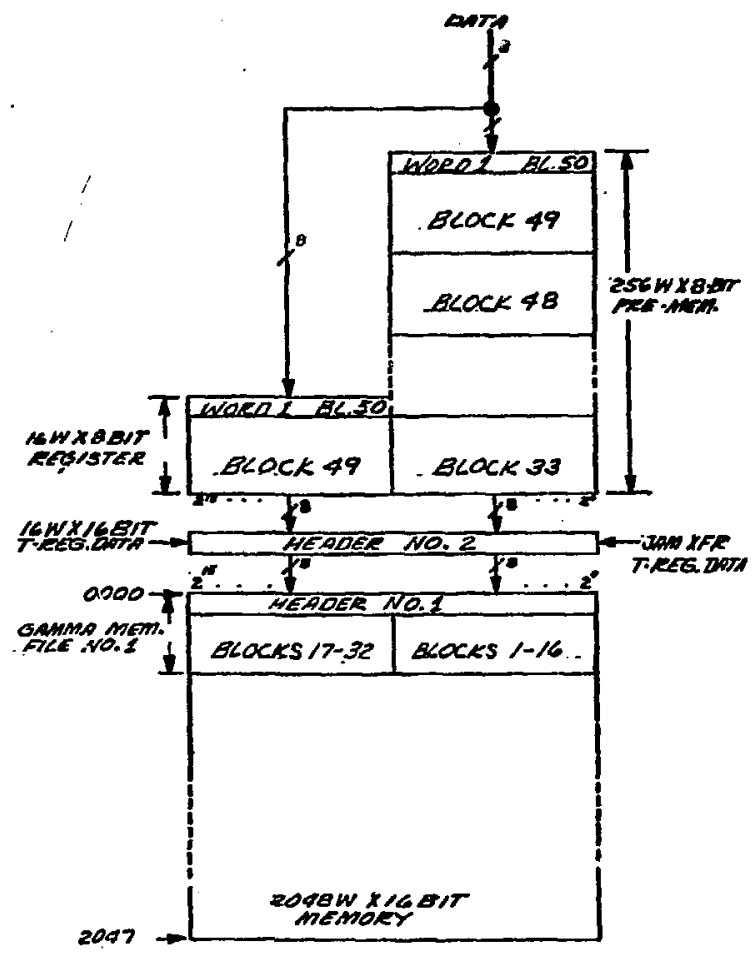

F1g. $c-3$.

Memory configuration just prior to entering the 2nd gamma memory file into the main memory.

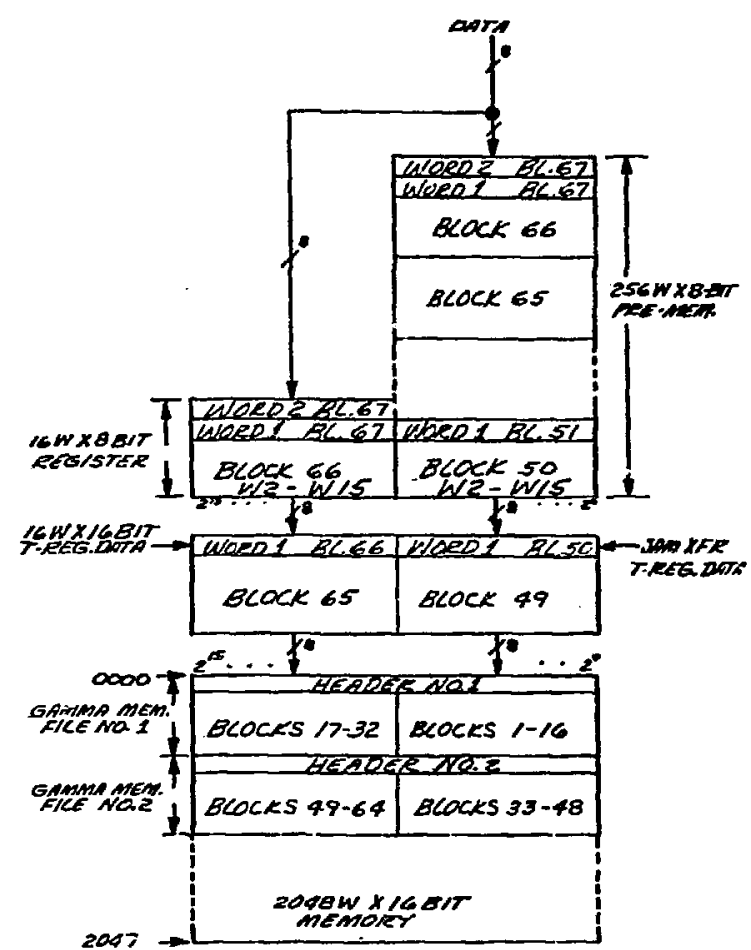

Fig. $\mathrm{C}-4$.

Memory configuration after transfer of the 2nd $\gamma$-memory file into the main memory. 


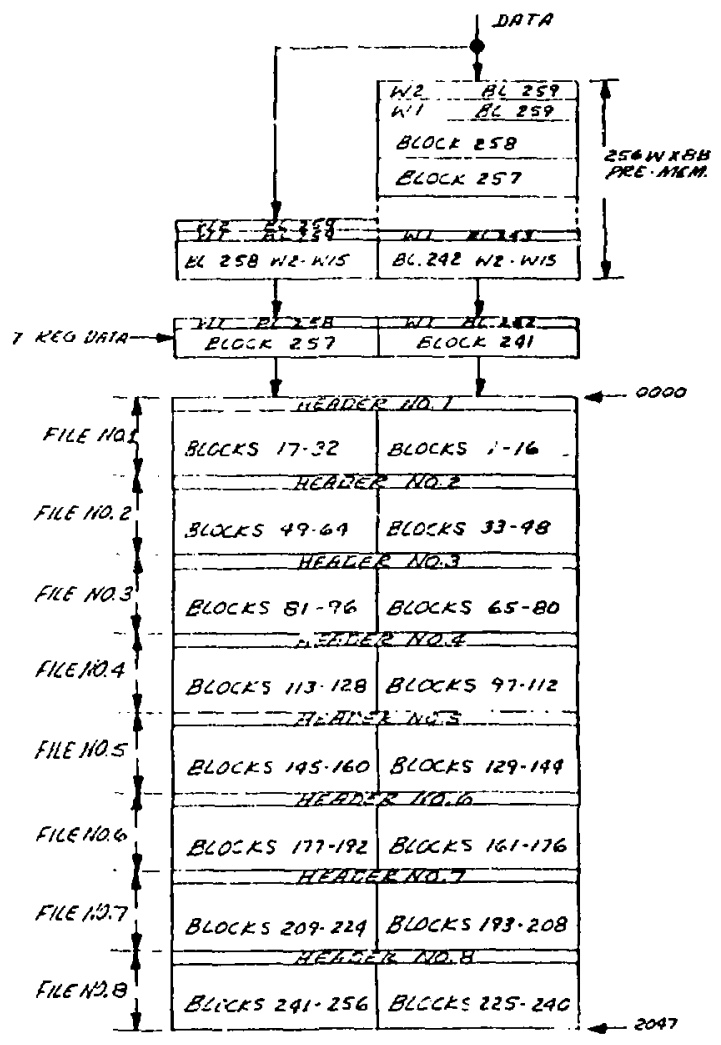

Fig. C-5.

Memory configuration when full. 